\title{
ORGANIC PHOTOVOLTAIC CELLS: HISTORY, PRINCIPLE AND TECHNIQUES
}

\author{
J. C. BERNÈDE
}

LAMP, FSTN, Université de Nantes, 2 Rue de la Houssinière, BP 92208, Nantes CEDEX 3, 44322, France.

(Received: December 4, 2007 - Accepted:

\section{SUMMARY:}

In this review we present an overview of the different organic solar cells families. After recalling shortly the specificities of organic materials, the band structure, the electronic properties and the charge separation process in organic materials are shortly described. Then the new organic solar cell concepts are presented. Plastic organic solar cells consist either of two organic layers or a homogeneous mixture of two organic materials. One of them - either an organic dye or a semiconducting polymer - donates the electrons. The other component serves as the electron acceptor. Principles of these multi-layers and bulk heterojunctions are presented and discussed. Then some typical examples are presented, showing the fast evolution of the cells performances. Finally, a specific attention is devoted to the interfaces electrodes/organics. Indeed recent results show that, at least in the case of multi-layers cells, the introduction of thin buffer layers at the interfaces cathode/organic acceptor and/or anode/organic donor, can strongly improve the efficiency of the organic solar cells. About the interface organic acceptor/cathode, we report the influence of an exciton-blocking layer and/or an $\mathrm{Al}_{2} \mathrm{O}_{3}$ thin layer on the efficiency of $\mathrm{CuPc} / \mathrm{C}_{60}$ based photovoltaic cells. The presence, or not, of a thin $\mathrm{Al}_{2} \mathrm{O}_{3}$ layer depends on the encapsulating process of the devices. In the case of glass/ITO/CuPc/ $\mathrm{C}_{60} / \mathrm{Al}$ cells, the presence of an $\mathrm{Al}_{2} \mathrm{O}_{3}$ thin layer at the interface "organic acceptor/aluminium" increases strongly the open circuit voltage of the cells but decreases slightly their short circuit current and fill factor. In the case of glass $/ \mathrm{ITO} / \mathrm{CuPc} / \mathrm{C}_{60} / \mathrm{Alq}_{3} / \mathrm{Al}$ cells, the open circuit voltage is systematically higher than without $\mathrm{Alq}_{3}$. However, in that case, the presence of $\mathrm{Al}_{2} \mathrm{O}_{3}$ does not improve significantly the cell performances. All these results are discussed in terms of series and shunt resistance values related to possible oxygen contamination and organic covalent action with the $\mathrm{Al}$ films. The effectiveness of these different phenomena depends on the presence, or not, of $\mathrm{Alq}_{3}$ and/or $\mathrm{Al}_{2} \mathrm{O}_{3}$ layers.

About the interface anode/organic donor, it is shown that an ultra thin metallic film improves significantly the short circuit current and the cell performances. The anode in plastic solar cells, which is a transparent conductive oxide (TCO), is usually an indium tin oxide film (ITO). Indeed, when a ZnO anode is used, cells performances are far from those achieved with ITO. However, strong improvement of the cells efficiency is encountered when an ultra thin buffer layer is introduced between the $\mathrm{ZnO}$ and the organic film. The presence of this ultra thin buffer layer at the surface of the TCO allows decreasing the performance difference between the cells using ITO and those using $\mathrm{ZnO}$. More generally such ultra thin buffer layer improves the solar cells performances.

\section{I: Introduction to the photovoltaic energy ${ }^{1}$ :}

\section{I-1. About the energy in the world:}

Availability to all citizens of safe and renewable energy in sufficient quantities is a prerequisite for a sustainable society. A clean energy is necessary to decrease the atmosphere contamination and the greenhouse gas (GHG) emissions to ensure people safety and security.

A renewable energy is necessary, meaning that the use of finite fossil resources has to be gradually replaced.

Therefore it is necessary to diversify the energy sources, mainly the renewable energies. It is a very urgent goal. Presently almost one thirds of the world population does not have access to electricity, while $20 \%$ of the world population of the developed countries use $80 \%$ of the world energy production. The very fast increase of the demand of the emerging countries highlights the urgency to develop renewable energies.

Up to day photovoltaic energy is the most expensive source (Table I), which implies investigation in the field of cheap materials, low processing costs, ease of large scale manufacture...

\begin{tabular}{|c|c|c|}
\hline & $\begin{array}{c}\text { Wold energy } \\
\text { production in } \\
2003(\mathrm{TWh})\end{array}$ & $\begin{array}{c}\text { Electricity costs } \\
\text { in 2003 }(€ \text { cents/ } \\
\mathrm{kWh})\end{array}$ \\
\hline Hydroelectricity & 3000 & $2-8$ \\
\hline Bio-energy & 175 & $5-6$ \\
\hline Wind energy & 75 & $4-12$ \\
\hline Geothermal energy & 50 & $2-10$ \\
\hline Marine energy & 0.5 & $8-15$ \\
\hline Solar thermal energy & 0.8 & $12-18$ \\
\hline Photovoltaic energy & 2.5 & $26-65$ \\
\hline Renewable energies & 3300 & \\
\hline Total electrical energy & 15000 & $2-3.5$ \\
\hline
\end{tabular}

Table I: Energy production and cost [1].

\section{I-2. Current status of photovoltaic energy:}

The total solar power production reach $1.7 \mathrm{GW}$ for 2005 , that is to say less than à. $01 \%$ of the total global power demand. However this is a big hike on the
2004 figure of $1.2 \mathrm{GW}$. In 2006, it is around $2.4 \mathrm{GW}$, representing year-on year growth of nearly $50 \%{ }^{2}$.

Commercial photovoltaic modules are mainly based on silicon. First, the wafer based crystalline silicon either monocrystals or multicrystals. Efficiencies of these modules are near $15 \%$. The energy pay-back time of such modules is typically around three years or $10 \%$ of the operational life time.

The other technology is based on thin films: amorphous silicon, cadmium telluride, copper-indium/gallium-selenide/sulphide (CIGS). Here also silicon is dominant. However, as amorphous silicon did not fulfil stability expectations, over the past decade the thin film market reduced from $15 \%$ (1995) to $5 \%$ to day.

The actual 40 to $50 \%$ annual expansion of production might reduce prices, however if crystalline silicon is still more than $90 \%$ of the cells production, the demand will exceed supply through the end of the decade and prices are likely to remain high. By the end of the decade solar power generation will have hit the $10 \mathrm{GW}$ mark. The disparity between this increase and the available crystalline silicon suggests that a substantial, widening gap in the market will exist for other technologies. At the moment these only account for $9 \%$ of solar power generation. In 2010, the proportion of solar power that comes from nonsilicon technologies will grow to $20 \%$, i.e. around $2 \mathrm{GW}$.

To day the use of compound semiconductor Copper indium gallium diselenide (CIGS) is spreading fast, it appears that 2007 is the year of CIGS. In 2006 the production was $8 \mathrm{MWp}$. The production capacity at the end of 2007 is around $350 \mathrm{MWp}$ with an effective production of $130 \mathrm{MWp}$ for the year ${ }^{3}$.

Therefore, if as shown above, the increase of the photovoltaic market induces price reduction, competitive price production requires transition from crystalline silicon to thin film technology.

Researches in two categories of technologies are under investigation:

- Option 1: primarily aimed at very high efficiency, while optimization cost: multi-junction cells, use of concentrators.....

- Option 2: primarily aimed at very low cost, while optimizing efficiency: organic solar cells, hybrid solar cells... micro or nano structured materials. Our centre of interest deals with this second option.

We are now going to develop the organic solar cells history, principles and technology.

\section{Organic photovoltaic cells history:}

First of all, it should be underlined that organic chemistry is knowing a strong development. Since 1965, the Chemical Abstracts Service (CAS) has been registering the number of known chemical substances. In 1965 this number was 211,934 in 2002 it was 37,000,000 and 80,000,000 in February 
2005. It shows that the chemistry of materials has been making remarkable progress, providing us with new knowledge. The most fascinating aspects of chemistry is that the discovery of single molecule or new group of molecules might hold the possibility of changing the world ${ }^{4}$. That is the quest for the Holy Grail of the all searchers involved in the field of organic solar cells

In 1839 Becquerel discovered the photovoltaic effect, i.e. he observed a photocurrent when platinum electrodes, covered with silver halogen were illuminated in aqueous solution (photoelectrochemical effect) ${ }^{5}$.

Photoconductivity in selenium was reported by Smith in $1873^{6}$.

The first observation of photoconductivity in organic compound (anthracene) was reported in 1906 by Pochettino ${ }^{7}$. Photoconductivity in the poly(N-vinyl-carbazole) (PVK) polymers was put in evidence in $1957^{\circ}$. During the same period the first inorganic photovoltaic cells were developed at Bell laboratories ${ }^{9}$. These cells were based on crystalline silicon, their efficiency was $6 \%$. Then, spatial research, which needs energy source, has boosted inorganic photovoltaic cells investigations. The efficiency has reached $24.4 \%$ for crystalline $\mathrm{Si}^{10}$ and $19.2 \%$ for CIGS thin films ${ }^{11}$. As discussed above, silicon based photovoltaic cells account for $99 \%$ of world production. However, even if the price of these cells has been dramatically reduced, it is still too expensive and photovoltaic energy account for less than $0.1 \%$ of the total world energy production.

Organic semi-conductors are a less expensive alternative to inorganic semiconductors, if low cost processes are used to grow the photovoltaic modules. Moreover they are less energy consumer.

During the 1970, 1980 decades many works have been done in that field ${ }^{12-15}$ however very low power conversion efficiencies were achieved $\left(10^{-60} \%\right)$ because of low concentration and mobility of free charge carriers.

During the last ten years a new and strong interest has been devoted to organic photovoltaic cells. Such new interest is motivated by two recent developments in the organic semi-conductor field. First it has been shown that the quantum efficiency of the electron transfer from an excited polymer to $\mathrm{C}_{60}$ is very high and the transfer is very fast ${ }^{16}$, which is promising for change carrier separation in PV cells. Secondly the development of efficient organic displays based on organic light emitting devices (OLEDs) has shown that organic electronic components are viable. Those displays are now developed using low cost technology and these new technologies development for OLED can be tested for PV solar cells realisation ${ }^{17}$. Therefore OLED technology allows drawing a research guideline in organic PV cells. It should be noted that nowadays the reverse is true ${ }^{18}$. Plastic (pure) organic solar cells are solid and consist either of two organic layers or a homogeneous mixture of two organic materials. One of them - either an organic dye or a semiconducting polymer - donates the electrons. The other component serves as the electron acceptor. Usually, a fullerene is used for this purpose. After the charges (the electron hole pair) have been separated, the holes are transported to the anode, while the electrons are transported to the cathode, to supply a direct current for the consumer load.

Devices fabricated from conjugated polymers $/ \mathrm{C}_{60}$ bi-layers yielded power conversion efficiencies of no more than $0.1 \%{ }^{19}$, due to limited interfacial contact area between the donor and acceptor layers. Few years ago, Shaheen and coworkers have reported solar cells from MDMO-PPV blended with PCBM with $2.5 \%$ efficiency ${ }^{20}$. Moreover, $\mathrm{CuPc} / \mathrm{C}_{60}$ bi-layer cell, with an exciton-blocking layer, yields a $3.6 \%$ efficiency ${ }^{21,22}$, which shows that bi-layer structures also allow achieving efficient energy conversion. Recently more than $5 \%$ efficiency has been announced for optimised structures in both devices families ${ }^{23,24}$. In the present review after a short recall of the photovoltaic effect in inorganic materials and of the characteristics of solar cells, we will present the specific band structure and electronic properties of organic materials. Then different cell structures and their improvement will be discussed. Finally some specific characterization techniques are shortly described.

\section{Photovoltaic effect and solar cell characteristics:}

The photovoltaic effect is based on photons absorption which induces electron hole pair formation (photoconductive effect (ㄷ)) followed by charge separation with the help of junction (®) (fig .1).

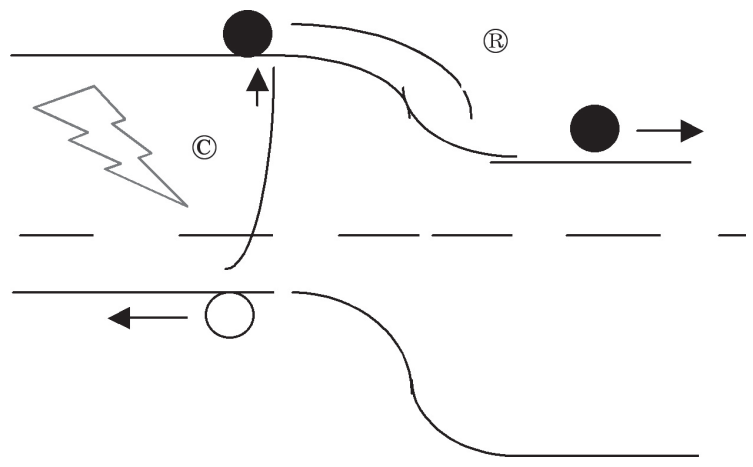

Figure 1: Photovoltaic effect.

The dark characteristics of such junction structure correspond to a standard diode. The ideal cell follows the thermoionic injection model ${ }^{25}$ :

$$
\mathrm{I}=\mathrm{I}_{\mathrm{s}}\left(\exp \left(\frac{q V}{k T}-1\right)\right)
$$

with $I_{s}$ : saturation current under reverse bias

q: elementary charge

$\mathrm{k}$ : Boltzmann constant

$\mathrm{T}$ : temperature $(\mathrm{K})$

$\mathrm{V}$ : bias $(\mathrm{V})$

Under light, an ideal cell can be represented by the equivalent circuit in figure $2 \mathrm{a}^{26}$.

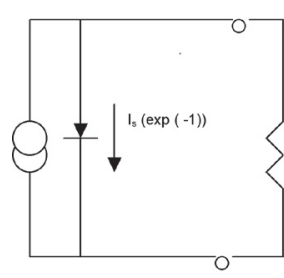

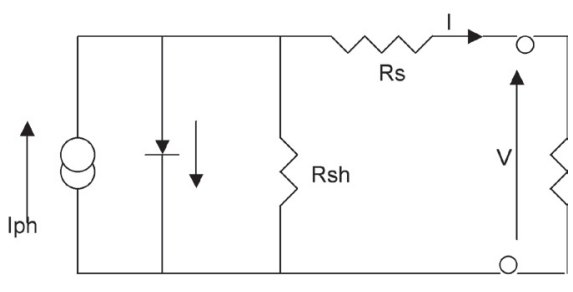

Figure 2: Equivalent circuit of: a- an ideal solar cell under light b- a real solar cell under light.

Therefore, under illumination, we have:

$$
\mathrm{I}=\mathrm{I}_{\mathrm{s}}\left(\exp \left(\frac{q V}{k T}-1\right)\right)-\mathrm{Iph}
$$

Iph is the photogenerated current.

In the reality, the equivalent circuit must take into account a serial resistance Rs, related to contact and bulk semiconductor resistances (fig 2c), and a shunt resistance Rsh, related to the no perfect diode contact (fig $2 \mathrm{~b}$ ). Rs and Rsh, induce losses, moreover an ideality factor $b$ should be introduced in the formulae (1), b being equal to 1 for an ideal diode. Finally we have:

$$
\mathrm{I}\left(1+\frac{R s}{R s h}\right)-\frac{V}{R s h}=\mathrm{Is}\left(\exp \frac{q}{b k T}(\mathrm{~V}-\mathrm{IRs})-1\right)-\mathrm{Iph}
$$

From the drawing of the current voltage characteristics of a photovoltaic cell under illumination, the different typical values can be measured (fig 3). The slopes at the short circuit point and at the open circuit voltage are the inverse values of the shunt resistance Rsh and the series resistance Rs of the equivalent circuit scheme of a solar cell respectively. 


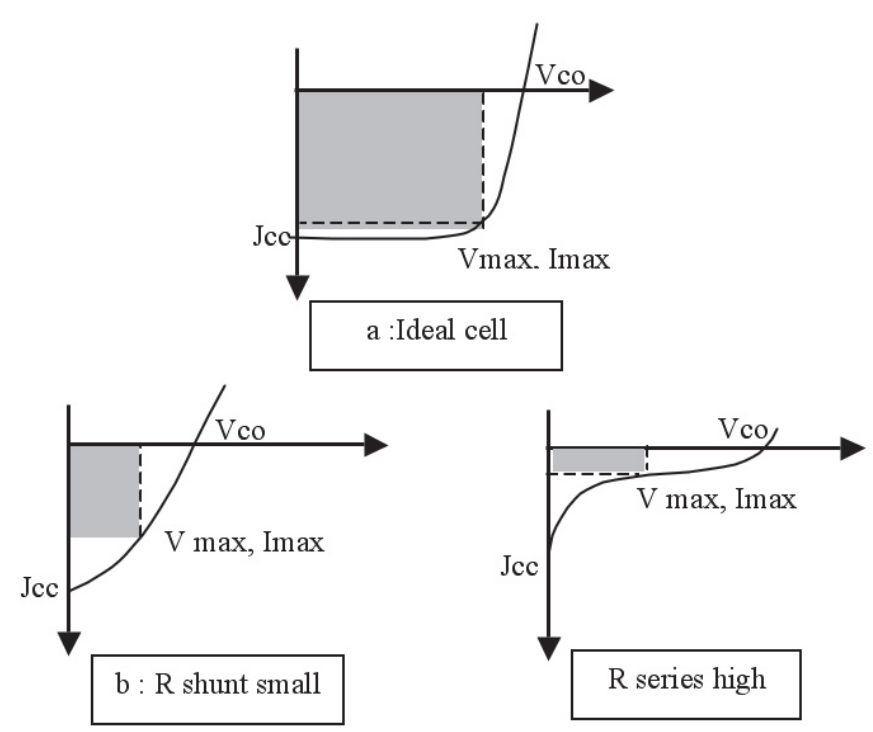

Figure 3: $\mathrm{I}-\mathrm{V}$ characteristics of a solar cell under illumination a -ideal cell $(\mathrm{Rs}=0, \mathrm{Rsh}=\infty)$

b -cell with small Rsh

c -cell with high Rs

Jsc corresponds to the short circuit current density, Voc to the open circuit voltage. Jmax and Vmax correspond to the maximum power Pm delivered by the solar cell.

A very important parameter is the fill factor FF defined as:

$\mathrm{FF}=\mathrm{Pmax} /($ Voc.Icc $)=($ Vmax.Imax $) /($ Voc.Icc $)$

Another important value in the study of cell performance is the Internal Photon to Current Conversion Efficiency (IPCE), it corresponds to the effectiveness of a solar cell to convert incident photons of a given wavelength into photocurrent:

$$
\mathrm{IPCE}=(\mathrm{hc} / \mathrm{e})(\mathrm{Jsc} / \lambda \mathrm{Pi})
$$

h: Planck constant

c: light velocity

Pi is the incident photon flux at the excitation wavelength $\lambda$.

Usually IPCE is given in percent and therefore [21]:

$$
\mathrm{IPCE} \%=1240 .(\mathrm{Jsc} / \lambda \mathrm{Pi})
$$

With Jsc in $\mathrm{Acm}^{-2}$, Pi in $\mathrm{Wcm}^{-2}$ and $\lambda$ in $\mu \mathrm{m}$.

Finally, the main parameter about cell performances is the power conversion efficiency $\eta$ :

$$
\eta=(\text { Vmax.Jmax }) / \text { Pin }=\text { FF }(\text { Voc.Jcc }) / \text { Pin }
$$

Pin is the incident photon flux (in $\mathrm{Wcm}^{-2}$ ), usually, typical conditions correspond to AM 1.5 i.e. Pin \# $100 \mathrm{mWcm}^{-2}$.

It can be seen fig $3 \mathrm{~b}$ that the main effect of a small Rsh value, i.e. diode with leaks and shorts, is decrease in Voc. An increase in Rs decreases Isc and FF (fig 3c).

IV. Specific band structure and electronic properties of organic materials:

Whatever the organic semiconductors, macromolecules dyes, dendrimers, oligomers, polymers..., they are all based on conjugated $\pi$ electrons. A conjugated system is based on an alternation between single and double bonds. The main properties related to this conjugation are that $\pi$ electrons are more mobile than $\sigma$ electrons. Therefore the $\pi$ electrons can move by hopping from site to site. These $\pi$ electrons allow light absorption (solar cells) and emission (OLEDs) in these conjugated organic materials. Molecular $\pi-\pi^{*}$ orbitals correspond respectively to the Highest Occupied Molecular Orbital (HOMO) and Lowest Unoccupied Molecular Orbital (LUMO).

In a crystalline inorganic semiconductor with a 3 dimensions crystal lattice the LUMOs and HOMOs form the conduction (CB) and valence band (VB) respectively. It is usually different in the case of the organic semiconductors. In that case intermolecular forces are weak Van der Waals forces and no large $\mathrm{CB}$ and $\mathrm{VB}$ are formed. Therefore the charge transport proceeds by hopping between localized states rather than transport within a band. This means that charge carrier mobility in organic materials is smaller than that in inorganic semiconductors. Moreover, in the case of polymers and oligomers there is hopping along the conjugated chain and intermolecular charge transport between adjacent polymer chains or molecules. The later hopping process involves mobility smaller than the former. Mobility is improved with the molecular ordering in the films, it is reduced by impurities as well as by oxygen traps. Therefore charge transport is improved by improving order (columnar liquid crystals, regioregular polymers), purification, high vacuum deposition and no oxygen contamination. However, for sake of simplicity, the organic absorber films can be regarded as a semiconductor-like material, where the band gap corresponds to the difference between the LUMO and the HOMO.

Photons absorption by inorganic semiconductors produces free electrons and holes, whereas photons absorption by organic semiconductors produces excitons, i.e. electron bounds to hole. It is from this optically excited neutral state that free charge pair can be provided. The charge separation is more difficult in organic semiconductors due to their low dielectric constant. Upon light absorption, molecules are excited from the fundamental $\mathrm{S}_{0}$ to the excited state $S_{1}$ (in the case of singlet transition). Singlet-singlet transitions are very efficient similar to direct transitions in inorganic semiconductors. They have short life time. They can go back to the ground state through luminescence or phonon emission. Therefore luminescence is a loss mechanism in photovoltaic cells. Another exciton decay channel is through a lower triplet state. Triplet excitons have an increased lifetime $(\mu s)$ because they cannot desexcite radiatively, it is equivalent to indirect transition, triplet state can diffuse over large distance up to $100 \mu \mathrm{m}$. Finally, singlet and triplet excitons can provide charges for PV cells.

Exciton dissociation can be promoted by charge transfer between donor and acceptor molecules. It is well known that exciton dissociation is efficient at the interface between materials with different electron affinity EA (i.e. LUMO) and ionisation potential IP (i.e. HOMO) (fig 4). The difference in electron affinities creates a driving force at the interface between the two materials that is strong enough to separate charge carriers of photogenerated excitons. EA and IP of the electron acceptor should be higher than those of the donor.

\section{Vacuum Level}

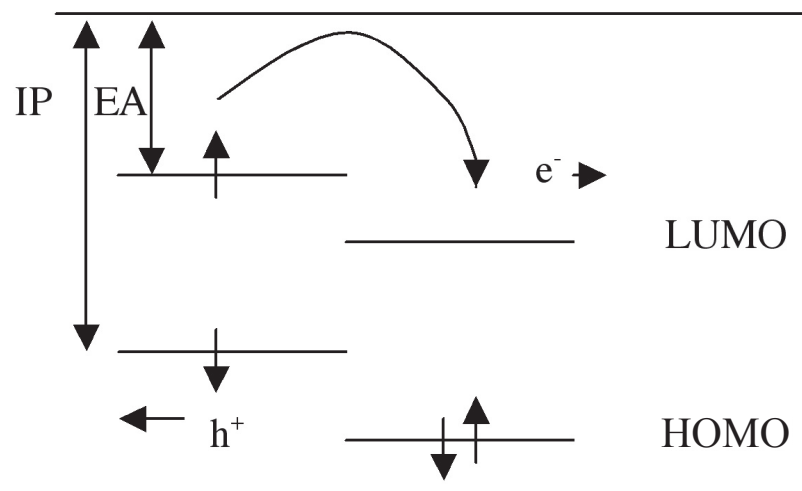

\section{Donor Acceptor}

Figure 4: Charge separation of an exciton into a free electro/hole pair at a donor acceptor interface.

\section{Organic photovoltaic solar cells requirements:}

As shown above the photovoltaic effect, i.e. the production of electric energy from sun light energy consists in different successive events.

First photons should be absorbed by the material, the exciton issued from this absorption should be dissociated, then the carriers have to be collected by the electrodes. 
- Photon absorption from the solar spectrum: it can be seen that optimum band gap $\mathrm{Eg}$ should be $1.1 \mathrm{eV} \leq \mathrm{Eg} \leq 2 \mathrm{eV}$. The majority of organic semiconductors have band gaps higher than $2.0 \mathrm{eV}$. However they can be, at least partly, managed by varying the polymer chain length and some macromolecules have their band gap around $1.7 \mathrm{eV}$. Moreover organic material have very high absorption coefficient so that only $100 \mathrm{~nm}$ are necessary to absorb between 60 to $90 \%$, if a reflexive back contact (such as aluminium) is used. Also some reflection losses should be present, anti-reflection coatings and structured surface of the device can be used.

- After photon absorption and exciton formation this exciton should reach a dissociation site i.e. either a semiconductor/metal or a donor/acceptor interface. Exciton diffusion range in organic materials before desexcitation is around $10 \mathrm{~nm}$, which means that the distance between an exciton creation site and a dissociation site (interface) should not be higher than $10 \mathrm{~nm}$.

- Charge separation: it occurs at organic semiconductor/metal interfaces, at impurities such as oxygen and at donor/acceptor organic interface, i.e. between materials with sufficiently different HOMO and LUMO respectively. The material with larger HOMO and LUMO will act as electron acceptor (A) and the one with smaller HOMO and LUMO value will act as electron donor (D). When the difference in HOMO and in LUMO is not sufficient the exciton may hop without charge separation. To achieve efficient charge separation we need:

$$
\Delta\left(\mathrm{LUMO}_{\mathrm{D}}-\mathrm{LUMO}_{\mathrm{A}}\right)>\text { Exciton energy. }
$$

- Charge transport and collection: As seen above charge mobility is very small and charges can recombine during the way to the electrodes, mainly if the same material serves as transport medium for both carriers' type. Also, interaction with defaults may limit the current. At last no blocking contact should be present at the interface organic semiconductor/electrode.

- Prevention from contamination: Organic materials for solar cells can dissociate if they come into contact with oxygen or humidity.

\section{New solar cell concepts:}

Such requirements and experience in the field of OLED devices, induce new solar cells concepts, they will be presented below. First, the different metal/semiconductor contacts are described.

\section{1. Ohmic and rectifying contact junctions:}

At the contact between two different materials, there is equalization of the chemical potential of the electron, i.e. of the Fermi level, in the two different materials. At the contact between a metal and a semiconductor either a rectifying Schottky or an ohmic contact is achieved.

If $\phi_{M}$ is the work function of the metal, i.e. its ionisation potential IP, and $\phi_{\mathrm{S}}$ the work function of the semiconductor, i.e. the energy difference between the Fermi level and the vacuum level, for the semiconductor we will have:

-in the case of n-type semiconductor

- a Schottky contact if $\phi_{M}>\phi_{\mathrm{S}}$, electrons diffuse from the semiconductor to the metal owing to small carrier density in semiconductors and to high carrier density in metals, a depletion layer appears in the semiconductor: there is a rectifying contact.

- an ohmic contact if $\phi_{\mathrm{M}}<\phi_{\mathrm{S}}$, electrons diffuse from the metal to the semiconductor. There is a negative accumulation in the $\mathrm{n}$ semiconductor, no barrier forms, the contact is ohmic.

-in the case of p-type semiconductor

- a Schottky contact if $\phi_{\mathrm{M}}<\phi_{\mathrm{S}}$, holes diffuse from the semiconductor to the metal. Owing to small carrier density in semiconductors and to high carrier density in metals, a depletion layer appears in the semiconductor: there is a rectifying contact.

- an ohmic contact if $\phi_{\mathrm{M}}>\phi_{\mathrm{S}}$, electrons diffuse from the semiconductor to the metal. There is a positive accumulation in the $\mathrm{p}$ semiconductor, no barrier forms, the contact is ohmic.

Of course in the case of n-type/p-type semiconductor contact, if $\phi_{\mathrm{scp}}>\phi_{\mathrm{scn}}$, which is usually the case, two depletion layers appear at the contact and a $\mathrm{p}-\mathrm{n}$ junction is grown.

Therefore an organic monolayer can make a Schottky junction with one of the electrodes. A bi-layer will mainly develop a p-n junction at the organic interface if there is a donor (p-type) and an acceptor (n-type) layer.

After this basic introduction on junction, the new cell concepts will be introduced through OLED structure.

\section{VI.2. New solar cell concepts and organic light emitting diodes:}

Basically the underlying principle of a photovoltaic solar cell is the reverse of the principle of OLED (fig $5 a$ and $b$ ).
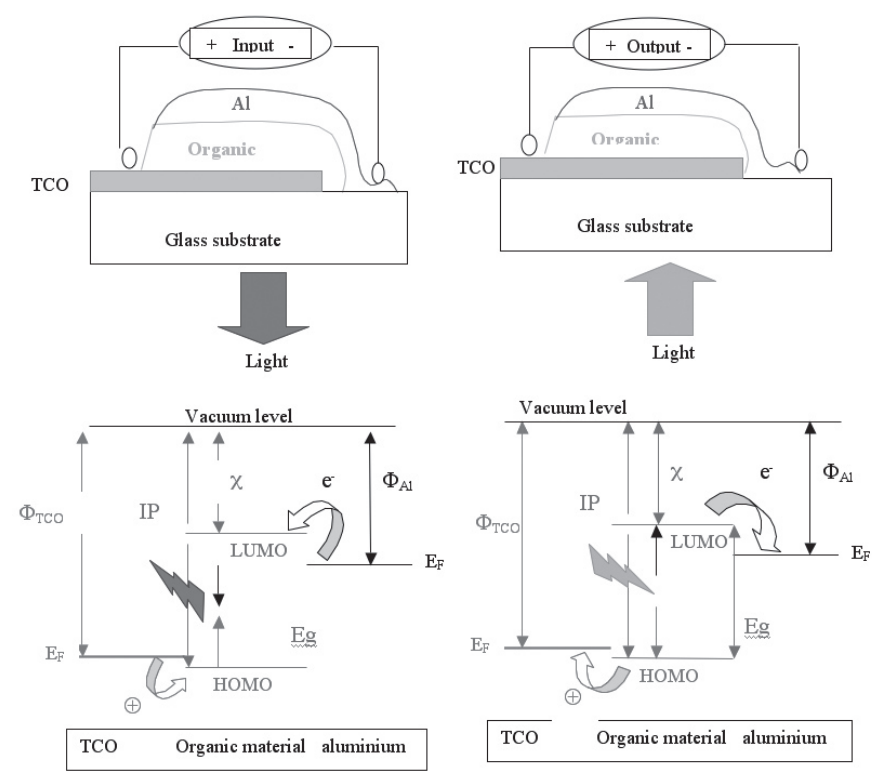

Figure 5: Principle of an OLED (left) and a solar cell (right) (Band scheme without contact)

In OLED, electrons are injected at the low work function electrode (cathode), while holes are injected at the high work function electrode (anode). At some point in the organic, the electron and hole meat and recombine with light emission. The reverse happens in a PV cell, when light is absorbed an exciton forms. After exciton dissociation, the electron must reach the low work function electrode and the hole the high work function electrode.

In fact, when the organic material is put into contact with electrode, the shape of the band scheme depends on the conductance of the organic material (fig 6).

When the cells are short circuited, the Fermi levels of the electrodes align. If the organic is an insulator, the field profile changes linearly through the cell (fig 6b). If the organic is a p-type semiconductor a depletion layer forms on the side of the metal with small work function, we have Schottky contact (fig. 6c).
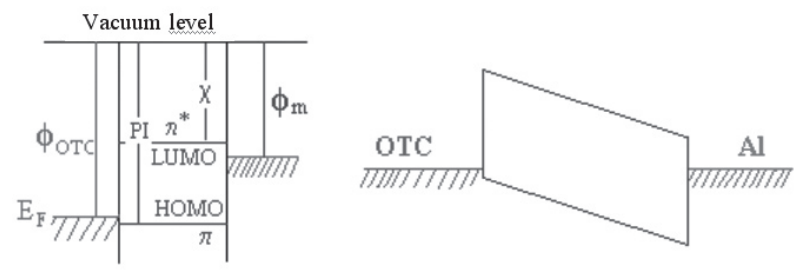

a: before contact

b: after contact, with an insulating organic material

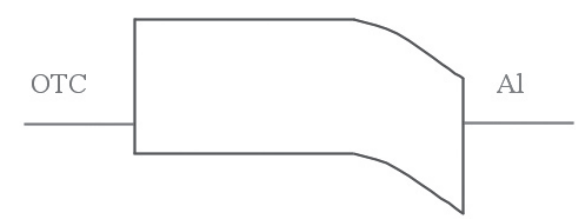

Vacuum level

a: before contact b: after contact, with an insulating organic material c: after contact, with an organic p-type semiconductor material

Figure 6: Band scheme of TCO/organic/Al structure 
Almost all organic photovoltaic cells have a planar layered structure, where the organic active layer(s) is (are) sandwiched between two different electrodes. One of them must be transparent. A transparent conductive oxide (TCO) is used, usually indium tin oxide (ITO) is the TCO, because it allows to achieve better results. The other electrode is very often aluminium, even if calcium has a better work function, because $\mathrm{Al}$ is stable in air while $\mathrm{Ca}$ is not.

From the above discussion it can be concluded that different device architectures can be developed.

- Single layer cells: An organic semiconductor is sandwiched between two electrodes, one of them gives an ohmic contact (TCO in the case of ptype organic) and the other one gives a rectifying contact. These cells are Schottky diodes with charge separation at the rectifying contact. Therefore the photoactive region is very thin (near the rectifying contact) and, since both positive and negative photoexcited charges travel through the same material, recombination losses are high. Such cells have small efficiency and are used only to study specific device properties such as current densities regimes through I-V characteristics ${ }^{27-29}$

- Bi-layers cells: different benefits can be expected from these structures. Efficient exciton dissociation by using well adaptated donor/acceptor material. Improvement of the photon absorption if the two organic materials overlap complementary domains of the solar spectrum. Mainly the use of bi-layers allows to benefit of separated charge transport layers, which decreases the recombination probability of the carrier. However the active domain, i.e. the donor/acceptor interface, is still very small and only excitons near the depletion layer can reach it and become dissociated. Different improvement of this basic device will be presented below;

- Bulk heterojunctions: since typical diffusion lengths of exciton are in the range of $10 \mathrm{~nm}$, while the film thickness should be more than $100 \mathrm{~nm}$ in order to absorb most of the light, it limits the cells efficiency. This difficulty has been overcome by using the new concept of bulk heterojunction ${ }^{20}$. These bulk heterojunctions are achieved by blending donor and acceptor. Blend cells exhibit a large interface area and most excitons reach the D/A interface.

Bi-layers and bulk heterojunctions will be developed with the help of many examples, electrode/organic interfaces will be also discussed. Different improvement possibilities will be presented and discussed.

\section{The concept of bi-layer heterojunctions:}

As discussed above the idea behind an heterojunction is to use two materials with different electron affinities and ionisation potentials. This will favour exciton dissociation, the electron will be accepted by the organic material with the larger electron affinity and the hole by the one with the lower ionisation potential (figure 7).

In such a cell if the LUMO acceptor $\left(\mathrm{LUMO}_{\mathrm{A}}\right)$ is sufficiently higher than the LUMO donor $\left(\mathrm{LUMO}_{\mathrm{D}}\right)$, the excited electron will relax into the acceptor LUMO and separate from the hole. For sufficient LUMO difference the charge separation is much more efficient at the donor-acceptor interface than at the electrode interface [30].

Since it has been reported the observation of an ultra fast reversible, metastable photo induced electron transfer form conjugated organic into Buckminsterfullerene, $\mathrm{C}_{60}$ is often used as acceptor in heterojunctions.

The first attempt MEH-PPV/C60 has been done in $1993{ }^{22}$. It has been shown that presence of the $\mathrm{C}_{60}$ layer increased more than 20 fold the photocurrent. Different polymers have been used since this first report ${ }^{28}$.

Moreover different acceptors have been tested. ITO/PPV/Perylene derivative/Al bi-layer allows to achieve efficiency of $1 \%$ under monochromatic illumination ${ }^{31}$. If $\mathrm{C}_{60}$ has been used with polymer, it has also been tested with organic molecular materials such as phthalocyanines $(\mathrm{Pc})$. It has been shown that, when $\mathrm{C}_{60}$ and oxotitanium phthalocyanine (OTiPc) are used, there is formation of a p-n junction at the interface $\mathrm{Cr}-\mathrm{Au} / \mathrm{C}_{60} / \mathrm{OTiPc} / \mathrm{ITO}$, cells achieve efficiencies of about $710^{-3} \%=\eta$, if a thin $\mathrm{SiO}_{2}$ insulator is inserted between OTiPc and the electrode ${ }^{32}$. Phthalocyanines, such as copper phthalocyanine $(\mathrm{CuPc})$, have been used also with some perylene derivative. ITO/CuPc/Perylene derivative/Ag p-n junction cell showed a $1 \%$ power conversion efficiency ${ }^{33}$.

Different improvements of the solar cells architecture have been tested. While a $\mathrm{p}-\mathrm{n}$ junction is used for exciton dissociation, the absorption spectrum of the photosensitive layer, the p-type poly(3-butylthiophene), has been extended by adding a dye which absorbs in the visible region ${ }^{34}$. The dye belongs to the indione group -PR3072- and a perylene derivative called MPP is used as n-type layer. Such hybrid molecular/polymeric $\mathrm{p}$-n type junction provides a $0.15 \%$ efficiency. Another possibility is to improve the number of organic layer to create multi-steps electron transfer system by overlaying organic dye layers in the order of ionisation potential. Takahashi and co-workers ${ }^{35}$ use a photosensitised film between an electron acceptor layer and a strong electron donor layer. The photosensitised is an heterodimer consisting of a weak electron donating and a weak electron accepting prepared by mixing each dye in solution. Such cell configuration allows to achieve energy conversion yield of $3.5 \%$ when irradiated with $445 \mathrm{~nm}$ monochromatic light of $12 \mu \mathrm{w} \mathrm{cm} \mathrm{cm}^{-2}$. c: Cross section
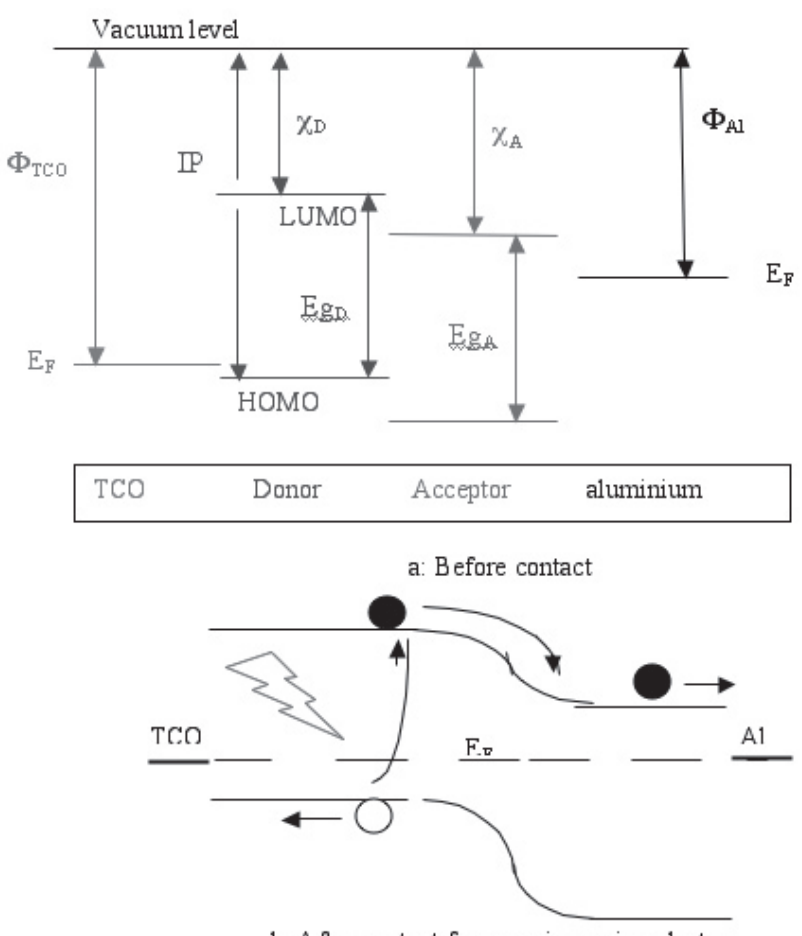

b: After contact for organic semiconductor

Al

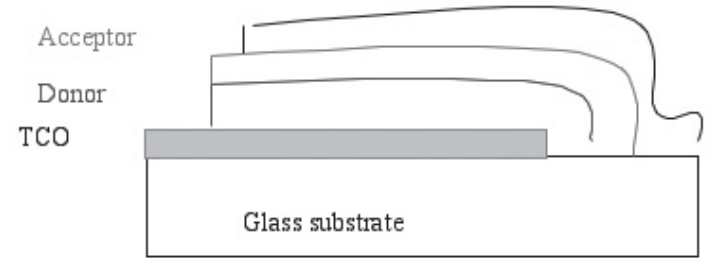

Figure 7: Bi-layer structure band schemes (a, b) and cross section (c).

Pfeiffer and $\mathrm{col}^{36,37}$ have developed a p-i-n technology using high vacuum deposition process. Efficiency of $3.8 \%$ have been obtained. But this has been achieved using more than two organic layers. Indeed, as will see later in this review, the best results have been obtained using multilayer structures based on the couple $\mathrm{CuPc} / \mathrm{C}_{60}$. However it can be already said that bi-layer structure allows to achieve higher efficiency than single layer Schottky structure. While progress should be expected with that cell family, which will be discussed at the end of the review, another solar cells architecture seems very promising: the bulk heterojunctions.

\section{The concept of bulk heterojunctions:}

Since for effective light absorption, the organic semiconductor film thickness should be at least $100 \mathrm{~nm}$, since the typical diffusion length of the exciton is $10 \mathrm{~nm}$ and since the exciton dissociation is effective at donor/acceptor interface, one possible answer is to use a blend of the donor and the acceptor, this is the concept called "bulk heterojunction" ${ }^{38}$ (fig 8). 


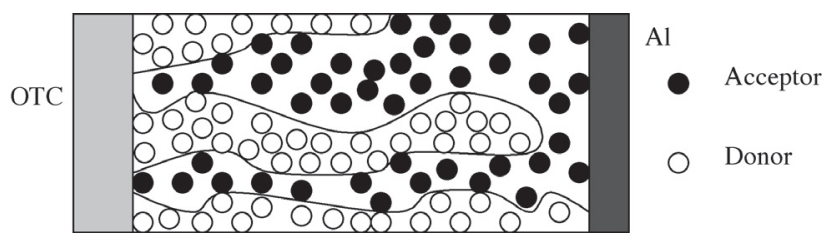

Figure 8: Schematized bulk heterojunction.

The first difficulty encountered in such dispersed heterojunction is that of solid state miscibility and stability. Usually organic conjugated systems are not miscible. Therefore the blend should be fabricated out of equilibrium. Spin coating, co-evaporation can be used.

The first dye/dye bulk heterojunctions were reported in 1991 by Hiramoto and $\mathrm{col}^{39}$.

In $1994 \mathrm{Yu}$ and $\mathrm{col}^{40}$ report on the first dispersed polymer heterojunction ITO/MEH-PPV: $\mathrm{C}_{60} / \mathrm{Ca}$. The photosensitivity of the polymer was an order of magnitude larger than that of pure polymer. The blend has been deposited by spin-coating. One limitation was the low solubility of fullerenes. In 1995 Hummelen et al ${ }^{41}$ synthesized different $\mathrm{C}_{60}$ derivatives with high solubility, which allows to obtain blend with up to $80 \%$ of $\mathrm{C}_{60}$ derivative. The $\mathrm{C}_{6}$ derivative the most used is the Phenyl-C61-butyric acid methyl ester (PCBM)

It should be noted that, in bulk heterojunctions, the electrodes represent selective membranes for the respective charges (fig 9).

When donors and acceptors are in contact with TCO and Al respectively, carriers can easily go away from the bulk heterojunction (fig 9a), but when donors and acceptors are in contact with $\mathrm{Al}$ and TCO respectively a barrier potential is present at each interface (fig 9b), which forbids any leakage current.

The MDMO-PPV blended with PCBM has been used with success by Hummelen, Brabec, Saricifti et al of the University of Linz. They achieved power conversion efficiency of $2.5 \%$ under AM 1.5 irradiation ${ }^{42,43}$ and now, as we will see below, after morphology improvement, $6 \%$ efficiency has been announced. In order to try to stabilize the blend they have shown that addition of $11 \mathrm{wt} \%$ of polystyrene does not alter the device characteristics ${ }^{44}$. They have shown that the morphology of the interpenetrating networks of conjugated polymers with fullerenes plays a critical role ${ }^{45}$. Degradation mechanisms appear to have a morphological component ${ }^{46}$.

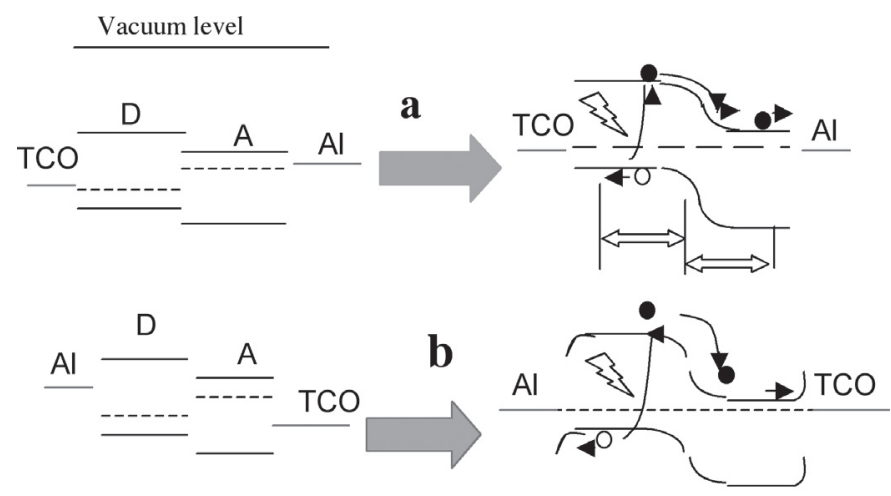

Before contact

After contact

Figure 9: Bulk heterojunctions, different possible contacts

In order to achieve high efficiency solar cells, the nanometer morphology of the bulk heterojunctions should facilitate both, the photo induced creation of mobile charge carriers (the optimum density of donor/acceptor interfacial contact) as well as transport of the carriers to the electrodes (necessity of continuous path ways for each carrier type).

In the classical MDMO-PPV: PCBM active layer, holes are transported through the conjugated polymer matrix, and electrons are transported by hopping between fullerene molecules. Importantly these two different charge transport processes do not interfere with each other. AFM studies have shown that MDMO-PPV: PCBM blend films spin coated using toluene as solvent are less homogeneous than those issued from chlorobenzene solution, this should be related to the fact that the solubility of PCBM in chlorobenzene is more than twice than in toluene. Moreover $\mathrm{I}_{\mathrm{SC}}$ of the cells obtained with chlorobenzene as solvent is twice that of cells obtained with toluene as solvent. Also FF increases. The increased $\mathrm{I}_{\mathrm{SC}}$ and $\mathrm{FF}$ due to improved morphology yield a nearly 3 -fold increase in the AM 1-5 power conversion efficiency ( $0.9 \%$ versus $2.5 \%)^{47}$. Since both thin films exhibit similar optical absorption spectra, it can be concluded that the organic film morphology have large influence on cell efficiency.

Different PPV blends have also been tested such as MEH-PPV blended with a perylene derivative. It is shown that annealing enhances the quantum efficiency probably through electron conducting perylene crystal grow ${ }^{48}$. Blend could be used in three organic layer devices. As an example, $30 \mathrm{~nm}$ thick $\mathrm{C}_{60}: \mathrm{ZnPc}$ composite film has been introduced between a donor $(\mathrm{ZnPc})$ and an acceptor (MPP-perylene derivative) which allows to achieve an efficiency of $1 \%{ }^{49}$. Some attempts have also been done with polymer-polymer blend. A power conversion efficiency $\eta=1 \%$ was given by M3EH-PPV:CN-etherPPV blend ${ }^{50}$. Higher conductivity is expected in columnar films. ITO/blend/Al cells using liquid crystals have been probed. The blend was the soluble liquid crystal HBC-PhC12 with a perylene derivative. A power efficiency maximum of nearly $2 \%$ was achieved at $\lambda=490 \mathrm{~nm}^{51}$

It is known that one difficulty of the blends is their "demiscibility". One possible way to control a bicontinuous phase separation and insure a large interfacial area between donor and acceptor is to covalently graft fullerene moieties into the donor polymer backbone ${ }^{52}$. Phthalocyanine fullerene dyad $\left(\mathrm{Pc}-\mathrm{C}_{60}\right)$ is an intermolecular donor-acceptor in photovoltaic devices ${ }^{53}$. However, if the photocurrent increases around $700 \mathrm{~nm}$, the low short circuit currents of the devices indicate charge transport problems. Similar attempt using mono-substituted quaterthiophenes bearing strong electron-withdrawing group gives small efficiency ${ }^{54}$

In that field many ideas have been submitted. The synthesis of dye linked conducting polymers allows to obtain a photovoltaic effect but with very small efficiency ${ }^{55}$

Sun ${ }^{56}$ proposes a bridge-donor-bridge-acceptor-type of block copolymer, where donor and acceptor are conjugated polymer blocks and bridge is a non conjugated and flexible chain, in different configurations, however this concept has to prove its efficiency.

Therefore, up to now, the use of a blend donor acceptor seems the more promising. PPVderivatives:PCBM blends have been systematically studied, it has been shown that limitation in cells performances are related to organic materials themselves. A study of the influence of the MDMO-PPV:PCBM ratio has shown that, in the experimental range studied, if an increase of the PCBM content increases the charge carriers mobility $\mu$ up to two orders of magnitude, simultaneously, the lifetime of the charge carriers $\tau$ decreases in the same proportions in such a way that the product $\mu \tau$ stays nearly constant whatever the blend composition is ${ }^{57}$. There are several parameters which influence the organic cells performances. The first of them is the absorption efficiency of the photons of the solar spectrum. PPV derivatives are well known to have band gap at least higher than $2 \mathrm{eV}$. Therefore to achieve a better overlap with the solar spectrum, polymer with smaller band gap should be used. Polymer with low band gap, that is to say smaller than $2 \mathrm{eV}$, are therefore necessary in order to improve the solar cells performances. A review of such polymers has been proposed by E. Bundgaard and F.C. Krebs ${ }^{58}$. Most of the low band gap polymers encountered in the literature are based on thiophene. Effectively the substitution of a polythiophene derivative to the PPV derivatives has allowed achieving to achieve higher power conversion efficiencies. The poly(3-hexylthiophene), P3HT, has a band gap of $1.9 \mathrm{eV}$ and it is one of the thiophene derivatives which has been systematically investigated. As in the case of PPV, the electron acceptor is the PCBM. The film is deposited by spin coating. The procedure used during the blend deposition has a large influence on the properties of the deposited blend. The regioregularity of the P3HT is of great importance and therefore the solvent used is decisive ${ }^{59,60}$. Moreover it has been shown that the regioregularity and the molecular weight of the polymer have large influence on the device performance. Therefore many groups have proceeded to some annealing treatments in order to improve these properties. Thermal annealing allows improving the crystallinity of the polymer. During the annealing there is some spectral absorption broadening and an increase of the carriers mobility correlated with the increased crystallisation of the polymer ${ }^{61,62}$. Recently, efficiency higher than $6 \%$ has been announced using thermally annealed polymer blend based solar cell ${ }^{23}$. These cells have the classical structure ITO/PEDOT:PSS/P3HT:PCBM/LiF/Al. They have been probed in a dry nitrogen glove-box, then they have been annealed $8 \mathrm{~min}$ at $158^{\circ} \mathrm{C}$. The power conversion efficiency of these cells before annealing is $2.79 \%$ and $6.1 \%$ after annealing. It is shown that the efficiency of the annealing depends on the initial dispersion of the PCBM in the P3HT. When PCBM is introduced 
as relatively large aggregates the crystallisation of P3HT is hindered, when it is well dispersed, surface energy effects induce heterogeneous crystallisation with phase separation and continuous paths for both carrier types. In that case lower energies are required for carrier hopping, which justifies optimum performance. Many original treatments have been probed, each with some success. Zhao and col. ${ }^{63}$ have shown that when the samples are introduced into a jar filled with 1,2-dichlorobenzene (DCB) for half an hour before cathode deposition and annealed after, the cell efficiency is better than the one obtained when the cells are directly annealed without DCB vapour treatment. The improvement is mainly attributed to absorption spectrum of the blend. It can be concluded that DCB molecules can penetrate the blend increasing the space between the polymer chains allowing better ordering during annealing. Always with the same goal of optimum interpenetrating network, Wang and coll. have introduced a surfactant in the blend solution ${ }^{64}$. They use an oleic acid $(\mathrm{OA})$ and therefore the cells were based on a P3HT/PCBM/OA blend thin film sandwiched between the ITO anode and the $\mathrm{LiF} / \mathrm{Al}$ cathode. The device with $\mathrm{OA}$, after annealing at $155^{\circ} \mathrm{C}$ for $5 \mathrm{~min}$, has an efficiency of $4.3 \%$, while the device without $\mathrm{OA}$ has only $3.1 \%$ after the same annealing. Another possibility investigated to improve the blend morphology is the use of co-solvents ${ }^{65}$. It is shown that the best efficiency $(\eta=4.64 \%)$ is obtained, for the device made with 1:0.7 ratio of P3HT to PCBM and a dichloromethane:chloroform cosolvent. It should be noted that the drying process of the blend also influence the device performance. Moreover the interface cathode/organic donor has been improved and it will be presented in the chapter which discuss the effect of interface layers. Globally it can be said that, under specific loading and annealing conditions, a combination of morphological and electronic factors allows to achieve optimum power conversion efficiency ${ }^{66-69}$.

H. Kim, W-W. So and S-J. Moon have investigated the effect of annealing not only on blend structure but also on the interfacial properties between the active layer and the cathode ${ }^{70}$. They show that, when the annealing take place after deposition of the $\mathrm{Al}$ capping film, there is also some improvement of this interface through rougher interface morphology, which induces some increase of light scattering at the back electrode and significant improvement in the device performance.

Some ones have also tried to grow well crystallized blend without annealing. Thus, the use of a high boiling point solvent, which reduces the evaporation speed during deposition, allows to grow crystallized P3HT in P3HT-PCBM blend, which gives solar cells with good power conversion efficiency $(3.6 \%)^{71}$.

Some original polymer, polymer/electron acceptor molecules and even allpolymer solar cells have been probed ${ }^{72-74}$, even if some interesting results have been obtained, up to now the P3HT:PCBM blend is the better couple.

As a conclusion, if very interesting power conversion efficiencies have been measured, it has been shown that the performances of bulk heterojunctions solar cells depend strongly on the different steps of the production process, some of which being very difficult to perform with reproducibility as requested in an industrial fabrication. Therefore, at the same time to these works on blends, an increasing interest is devoted to multilayers heterojunctions.

\section{From the bilayer to the multiple heterojunctions devices:}

A lot of work have been devoted to the $\mathrm{CuPc} / \mathrm{C}_{60}$ couple which gives easily efficiency around $1 \%$. However, as said above, in such bilayer structures the organic film thickness necessary to absorb efficiently the photon is around $100 \mathrm{~nm}$, while, after photon absorption, the exciton mean free path is only around $10 \mathrm{~nm}$. Peumans and Forrest ${ }^{75}$ have shown that after the introduction of a thin organic layer of bathocuproine (BCP) between the $\mathrm{C}_{60}$ and the cathode electrode a significant improvement of the cells performances is put in evidence. With a device structure: ITO/PEDOT:PSS/CuPc/BCP/Al a power energy efficiency of $3.6 \%$ has been measured. They have called the BCP layer exciton-blocking layer (EBL). It is supposed that the BCP layer acts as an effective EBL layer, which blocks the diffusion of excitons to the cathode in such a way that this excitons confinement increases the probability of exciton dissociation. Since the BCP is a large band gap insulating layer, it was suggested that electron transport across the BCP layer occurs through states situated in the band gap. This states being introduced in the BCP band gap by damage induced during cathode deposition. In a systematical study Vogel and col. ${ }^{76}$ have shown that, more than an exciton blocking layer, the main contribution of the BCP layer is to improve interface properties as a protective film from cathode diffusion into the electron acceptor. Such explanation of electron BCP role justify an optimum thickness of around 7-8 nm. For thinner films the protection of the under layer is not effective, for thicker films the increase of the series resistance degrades cells performances. For fabricating large-area panel without electrical short, the EBL layer should be sufficiently thick. Therefore it has been proposed to used low-resistance organic compounds such as tris(acetylacetonato)ruthenium(III) $\left(\mathrm{Ru}(\mathrm{acac})_{3}\right.$ [77]. Efficient organic double heterostructure employing ( $\mathrm{Ru}(\mathrm{acac})_{3}$ with thickness higher than $30 \mathrm{~nm}$ have been achieved, while, using the same experimental conditions the cells performance are degraded quickly when $\mathrm{BCP}$ films thicker than $10 \mathrm{~nm}$ are used. Different others EBL have been probed with some success such as bathophenanthroline (Bphen) [78], 2-(4-biphenyl)-5-(4tert-bythyl-phenyl)1,3,4-oxidiazole (PBD) or butyl tris(8hydroxyquinolato) aluminium $\left(\mathrm{Alq}_{3}\right)^{79}$. All these results show the film used should be transparent across the solar spectrum to act as a spacer between the electron acceptor and the cathode and should not reduce the electron current, which implies an optimum thickness for each material.

By analogy with polymer/PCBM bulk heterojunctions many works have been devoted to the study of mixed small molecule organic solar cells. When deposited by co-evaporation the cells based on $\mathrm{ZnPc: \textrm {C } _ { 6 0 }}$ are quite disappointing, even if a mild annealing treatment improves significantly the cells performances ${ }^{80,81}$. Attempts to achieve bulk-heterojunction using small molecules yields devices with power efficiencies smaller than those achieve in multiplayer structures. It has been checked that, as expected for efficient solar cells, there is a strong quenching of the photoluminescence in these mixed layers. Therefore the low efficiency encountered should be attributed to poor charge transport in the amorphous mixed layer. Annealing of mixed layer can allow to achieve phase segregation and larger crystalline domains. However, this increase in crystallinity comes at the cost of an increase in film roughness and high pinholes density. One way to try to kept the advantage of both bilayer and interpenetrating network is to grow hybrid planar mixed molecular heterojunction (PM-HJ) solar cells consisting of a mixed layer of donor and acceptor molecules sandwiched between homogenous layers of the donor and acceptor materials (Figure 10) ${ }^{82-84}$.

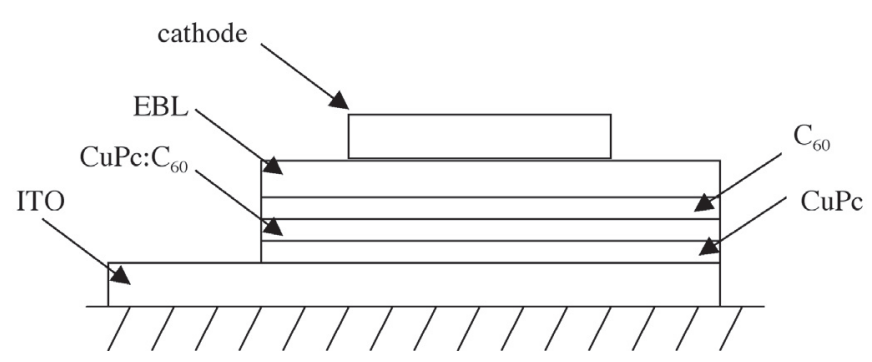

Figure 10: planar mixed molecular heterojunction (PM-HJ) device.

A maximum efficiency of $5 \%$ has been achieved using such PM-HJ, with thickness $15 \mathrm{~nm}, 10 \mathrm{~nm}, 35 \mathrm{~nm}$ for $\mathrm{CuPc}, \mathrm{CuPc}: \mathrm{C}_{60}, \mathrm{C}_{60}$ respectively. Therefore, an hybrid PM-HJ structure gives performances over those that use planar bilayer donor/acceptor junction or simple mixed heterojunctions. Charge conduction in mixture has been proven to be reduced by more than one order of magnitude compared to corresponding pure films. Therefore if a mixed layer can be used to improve charge separation efficiency it should be thin enough to avoid strong increase of the series resistance of the device. In order to try to avoid such conductivity degradation, a doped $\mathrm{CuPc}$ film has been substituted to the mixed CuPc: $\mathrm{C}_{60}$ film ${ }^{85}$. By using ITO/CuPc/CuPc:Rubrene/C60/Bphen/ $\mathrm{Al}$ structures, efficiencies of $5.58 \%$ are achieved. The rubrene absorption is complementary to $\mathrm{CuPc}$ and $\mathrm{C}_{60}$ absorption, which broadens the absorption spectrum and therefore improve the short circuit current.

As said above, Pfeiffer and col have developed a p-i-n technology using high vacuum deposition process ${ }^{36,86}$. First they have shown that it is possible to move the Fermi level of organic semiconductor by doping. Zinc-phthalocyanine has been doped using fully fluorinated tetracyano quinodimethane. Therefore they can reduce the series resistance and increase the photovoltage of organic solar cells. Then they have grown a $\mathrm{p}-\mathrm{i}-\mathrm{n}$ type heterojunction solar cell that reaches a power conversion efficiency of $2.4 \%$. The photoactive region is an evaporated zinc phthalocyanine $(\mathrm{ZnPc})$ and fullerene $\left(\mathrm{C}_{60}\right)$ film. Therefore the active layer use the bulk heterojunction concept. This film is sandwiched between two doped wide gap layers, which permits only one type of photoinduced charge carriers to be transported to the electrodes. The doping is realized by controlled co-evaporation of N,N,N',N'- Tetrakis(4-methoxyplenyl)-benzidine (MeOTPD) as matrix and tetrafluoro-tatrecyano-quinodimethane $\left(\mathrm{F}_{4}-\mathrm{TCNQ}\right)$ as dopant for the p-doped film and $\mathrm{C}_{60}$ as matrix and Leuco Crystal Violet (LCV) as dopant for the $\mathrm{n}$-doped layer. It should be noted that the $\mathrm{p}$ and $\mathrm{n}$ doped layers 
have conductivities 3 to 4 orders of magnitude higher than undoped layers. It should be noted also that all sublimations have been done in ultra high vacuum using Knudsen effusion cells. Optimised structures using TCO/PIN/M $/ \mathrm{PIN} /$ $\mathrm{M}_{2}$ tandems allow to achieve $3.8 \%$ efficiency ${ }^{37}$.

Indeed, since the short exciton diffusion length limits the thickness of the absorbing layer and therefore the cells performances, a solution can be the use of stacked cells $[24,87,88]$. In a first time "simple" ITO/CuPc/PTCDI/ $\mathrm{Ag} / \mathrm{CuPc} / \mathrm{PTCDI} / \mathrm{Ag}$ devices with a thickness of $0.5 \mathrm{~nm}$ for the Ag thin film allows an efficiency of $2.5 \%$. After photon absorption and exciton creation, this exciton can diffuse and dissociate at an electron donor/acceptor interface. After dissociation the holes are collected by the electrode in contact with the electron donor and the electron by the electrode in contact with the electron acceptor. Here we have two stacked cells, the front cells deposited onto ITO and the back cell in contact with the upper electrode. Thus the Ag central layer will provide a recombination zone for electrons coming from the front cells and the holes coming from the back cell. At the same time, holes in the front cell and electrons coming from the back cell are collected by the electrodes (Figure 11)

\section{$\mathrm{ITO} / \mathrm{CuPc} / \mathrm{PTCBI} / \mathrm{Ag} / \mathrm{CuPc} / \mathrm{PTCBI} / \mathrm{Ag}$}

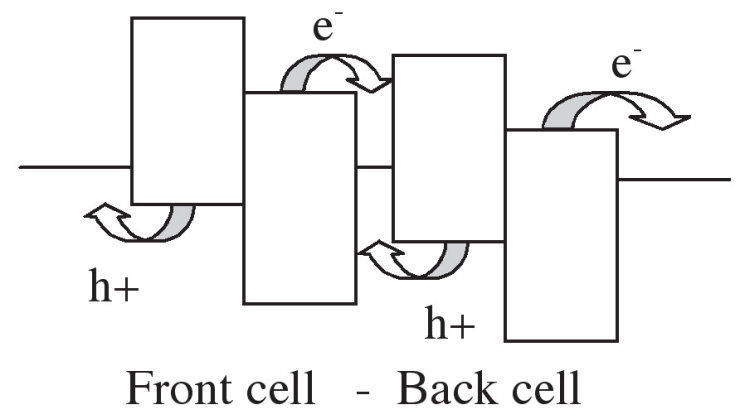

Figure 11: Energy level diagram of a two stacked cells after contact.

Therefore, the open circuit voltage of the structure is the sum of the open circuit voltage of each cell, while the short circuit current is the smallest of the currents produced by the front and the back cells. Hence similar photoreponse for each cell in the stack is essential to achieve high efficiency. In the case of dual cells the Voc is twice that of a single cell. Its efficiency is $2.5 \%$ while that of single cell is only $1.1 \%$, that is to say it is more than double in the case of dual cell, which can be attributed to an increase in total absorption as compared with single usual cell. A further improvement of the efficiency can be achieved by using planar mixed molecular heterojunction (PM-HJ) as front and back cells. After improvement of the interface between the two cells and using an EBL layer the structure based on two $\mathrm{CuPc} / \mathrm{CuPc}: \mathrm{C} 60 / \mathrm{C} 60 \mathrm{PM}-\mathrm{HJ}$ achieve the efficiency $5.7 \%$, such devices have been called asymmetric organic photovoltaic cells with hybrid planar mixed molecular heterojunctions ${ }^{24}$.

As shown above, similar photoreponse for each cell in the stack is essential to achieve high efficiency. Therefore, when the tandem structure is fabricated with the same donor/acceptor couple, the balancing for the photocourant generation can be obtained only by adjusting the layer thickness. Another possibility for the optimisation of the balancing of the photo-generated carriers is based on the spectral matching of the organic materials with different absorption. As example, in a triple-HJ solar cells, the investigation has been carried out by changing the material in the second cell ${ }^{89}$. The device was based on $\mathrm{CuPc} / \mathrm{PTCBI}$ (perylene 3, 4, 9, 10-tetracarboxylic bis-benzimidazole)

couple, while in the second some PTCDI (N,N'-diheptyl-3, 4, 9, 10tetracarboxylicdiimide) was introduced between the two other constituents. It is shown that the device efficiency varies with the second cell composition. In such triple-HJ, the balance of photocurrent generated in each cell is very important because the current of the device corresponds to the smallest current among these produced in each cell. Therefore the absorption profile of the material should be adjusted to optimise the current output, which is achieved here with thickness of $88 \mathrm{~nm}, 20 \mathrm{~nm}, 68 \mathrm{~nm}$ for CuPc, PTCDI, PTCBI respectively. In the same spirit, stacked cells constituted of a blend P3HT:PCBM for the front cell and of a $\mathrm{CuPc} / \mathrm{C}_{60} \mathrm{HJ}$ for the back cell have been probed. Such cell gives higher efficiency than the classical $\mathrm{CuPc} / \mathrm{C}_{60} / \mathrm{BCP}$ based cell ${ }^{90}$. Also, double and triple junction polymer solar cells processed from solution have been grown using MDMO-PPV:PCBM as active layer. The recombination layer, deposited between the active layers is fabricated by spin coating $\mathrm{ZnO}$ nanoparticles. The best results are achieved when an extremely thin $\mathrm{Ag}$ layer is evaporated on $\mathrm{ZnO}$. The Voc measured were around $0.8 \mathrm{eV}$, $1.4 \mathrm{eV}$ and $2.2 \mathrm{eV}$ in the case of single, double and triple junction respectively, which corresponds nearly to the expected sum of single cells ${ }^{91}$.

Analytical models suggest that power conversion efficiencies exceeding $12 \%$ can be obtained with the multiheterojunctions devices ${ }^{92}$, however the techniques necessary to grow such cells are quite sophisticated and other original ways are investigated. The couple pentacene $/ \mathrm{C}_{60}$ has been probed. It has been shown that post-fabrication annealing allows to improve the efficiency from $0.45 \%$ to $1.07 \%{ }^{93}$. The best efficiency has been obtained when a $\mathrm{BCP}$ layer is use as EBL with the couple pentacene/ $\mathrm{C}_{60}{ }^{94}$. Even if the result is still smaller (1.5\%) than those of $\mathrm{CuPc} / \mathrm{C} 60 / \mathrm{BCP}$ structures, the results are encouraging since up to now not many works have been done with this electron donor.

Another possibility is the use of discotic material. It is well known that the degree of order present in organic films influence strongly their electrical properties. Due to their structure made up of unidirectionally conducting wires, discotic materials can be used as conducting layers in organic devices. These materials are disk-shaped molecules that form columnar liquid crystals. When organized in columns they have far higher conductivity than when they are polycrystalline or amorphous. Therefore two layers organic photovoltaic cells can be grown using discotic materials with the goal of columnar growth. However, if such cells have shown a photovoltaic effect, columnar films are difficult to achieve. ${ }^{95,96}$.

Some attempts to use acceptor polymer films in bilayer photovoltaic devices, but without significant success, have been done ${ }^{97}$.

$X$. The open circuit voltage, influence of the presence or not of interfacial layers:

After the presentation of the last developments in the field of multilayers heterojunctions, a special attention will be devoted to the open circuit voltage of the organic solar cells and to the influence of the introduction of interfacial layers between the electrodes and the organic materials .

An interesting result in the bulk heterojunction is the measure of unexpected high open circuit voltage Voc. Before to discuss this phenomenon, the Voc of the other cell configurations are briefly reviewed.

In the case of single layer, devices with high purity insulating films work as a Metal 1/Insulator/Metal 2 (M1-I-M2) devices with Voc $\leq \phi_{\mathrm{M} 1}-\phi_{\mathrm{M} 2}$. If the organic film behaves like a semiconductor the devices work as a Schottky diode with Voc $\leq \phi_{M}-\phi_{S C}$ as discussed above. However interface dipole can modify, the expected behaviour of the organic/metal interface ${ }^{98}$.

It seems that the experimentally observed Voc of bulk heterojunction cannot be explained by the M1-I-M2 picture alone (Voc $\leq \phi_{\mathrm{M} 1}-\phi_{\mathrm{M} 2}$ ), for the typical ITO/Polymer: Fullerene/Al device, Voc is around $800 \mathrm{mV}$ or higher, while $\phi_{\mathrm{ITO}}-\phi_{\mathrm{H}} \cong 400 \mathrm{mV}^{47}$. Therefore there is a controversy concerning the driving force for charge separation under short circuit conditions. It should be noted that the HOMO level of the conjugated polymer matches well the work function of the ITO contact, therefore the hole injection/extraction into/from the polymer network is expected. Similarly, the electron, injection/extraction from Al electrode into/from fullerene network is efficient. The loss of the potential energy of a photo excited electron, and therefore of the maximum Voc during the charge transfer, occurs due to a high electro negativity of the fullerenes relative to conjugated polymer ${ }^{99}$ (Figure 12).

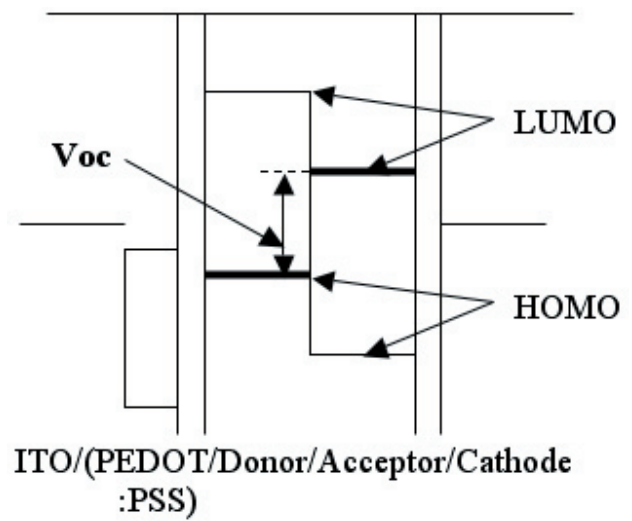

Figure 12: Band scheme of a ITO/D:A/Al structure before contact 
In front of the controversy on the Voc origin, Brabec and col ${ }^{47,100-102}$ have systematically studied the influence of the variation of different parameters on the Voc value.

-Variation of the acceptor, using different fullerene derivatives with varying acceptor strength they have measured the variation of Voc, the same polymer being used. It is shown that when the variation in the first reduction potential of the acceptor is $200 \mathrm{mV}$, the variation in Voc is 760 to $560 \mathrm{mV}$.

-Variation of the metal electrode material. When the work function of the metal of the electrode varies from $2.87 \mathrm{eV}(\mathrm{Ca})$ to $5.1 \mathrm{eV}(\mathrm{Au})$, i.e. when the work function varies by more than $2.2 \mathrm{eV}$, Voc varies from $814 \mathrm{mV}$ (Ca) to 650 $\mathrm{mV}(\mathrm{Au})$ i.e. a variation smaller than $200 \mathrm{mV}$.

-Variation of the transparent conductive electrode. As we will see below, often, at the interface TCO/donor, a thin PEDOT: PSS (poly $(3,4-$ ethylenedioxythiophene) doped with poly(styrenesulfonate)) is deposited by spin coating. The $\phi_{\mathrm{M}}$ of PEDOT:PSS can be modified electrochemically [103]. As shown in the case of OLED, a thin PEDOT: PSS film at the interface ITO/ organic improves the device performance. One of the hypothesis is that the ITO, which exhibits rough surface is smoothed out by the spin coated PEDOT: PSS, moreover the presence of this thin conductive polymer film between ITO and organic avoid direct contact between the oxygen of the TCO and the organic material. Also the work function of PEDOT: PSS $\left(\phi_{\mathrm{M}}=5.1 \mathrm{eV}\right)$ allows to decrease the barrier height at the interface.

It has been shown that the work function of PEDOT: PSS can be modified by electrochemistry, which allows to study the influence of the $\phi_{M}$ of the cathode on the cell properties. The adjustment of the work function has been done by electrochemical treatment, which allows fine adjustment [103], because of the correspondence of electrochemical potential and work function. Usually, a difference of $4.7 \mathrm{eV}$ between electrochemical potential and work function is assumed if the reference electrode is the $\mathrm{Ag} / \mathrm{AgCl}$ (see below chapter XI.3). The doping level was carried out by a potentiostatic electrolysis at fixed potential between 0 and $0.65 \mathrm{~V}$. The redox modification remains stable even into the dry state. The work function $\phi_{M}$ has been measured by UPS (see below chapter XI.2). It is shown that when the electrochemical equilibrium potential varies from 0.05 to $0.59 \mathrm{~V}$ the work function of PEDOT: PSS varies from 4.7 to $5.3 \mathrm{eV}$. It is found that the built in potential Vbi of the structure varies linearly with $\phi_{M}$ of the PEDOT: PSS, which shows that there is not any pinning effect of the $\phi_{M}$ of the PEDOT: PSS.

All these results can be discussed as follow ${ }^{47}$. The behaviour of the two interfaces is different. A variation of the work function of the positive electrode (ITO/PEDOT) linearly influence the Voc of the solar cells, while a variation of $\phi_{\mathrm{M}}$ of the negative electrode of $2.2 \mathrm{eV}$ results in a weak variation (less than $200 \mathrm{mV}$ ) of Voc.

Moreover a variation of the HOMO of the acceptor results in a linear change of Voc with a scaling factor of 1 . Therefore Voc varies with the conduction band of the acceptor and the work function of the positive electrode. More specifically, in the case of fullerene derivative acceptor, the open circuit voltage of the devices was found to correlate directly with the acceptor strength of the fullerenes, while it is rather insensitive to variations in the work function of the negative electrode metal. These results suggest that the quasi-Fermi level of the fullerene pins the Fermi level of the evaporated negative metal contact via surface charges. To summarise in the case of ohmic contacts, the negative and positive electrodes match the LUMO of the acceptor and the HOMO of the donor respectively, which governs the Voc $\left(V_{0 c} \leq \mathrm{LUMO}_{-}-\mathrm{HOMO}_{\mathrm{D}}\right)$, for non-ohmic contacts the experimental Voc depends also on the work functions if there is not pinning effect. Following Blom and col. this behaviour is in full agreement with the MIM concept ${ }^{104}$. They also suggest that that a pinning effect of the Fermi level is not really necessary to justify the faint sensibility of the Voc value with the work function of the cathode. Indeed they have shown that when the metal work function is sufficiently small to be below the LUMO of the acceptor, the electrode work function remain pinned close to this LUMO, which explains that the Voc values measured with $\mathrm{Al}\left(\Phi_{M}=4.2 \mathrm{eV}\right)$ or $\mathrm{Ca}\left(\Phi_{\mathrm{M}}\right.$ $=2.9 \mathrm{eV}$ ) are quite similar, the LUMO of PCBM being $3.7 \mathrm{eV}$. Moreover they recall that when a palladium cathode is used the Voc value decrease of 0.5 $\mathrm{eV}$.

As propose above, in order to have efficient charge transfer at the interface donor/acceptor, the band offset for the LUMO and the HOMO $\left(\Delta_{\text {номо }}\right.$ and $\left.\Delta_{\text {LUMO }}\right)$ should be greater than the exciton binding energy $\mathrm{E}_{\mathrm{B}}$. More precisely, the optimum $\Delta_{\text {номо }}$ and $\Delta_{\text {Luмо }}$ value of the orbital offset should be close to the sum of the exciton binding energy plus the charge separation reorganisation energy ${ }^{105}$. There is some constraint in the use of small band gap polymer proposed above. If small band gap polymers allows better absorption of the solar spectrum, which should increases the current density, the efficiency depends also of others parameters such as the open circuit voltage. We have seen that the maximum value of $\mathrm{Voc}$ is $\mathrm{Voc} \leq \mathrm{LUMO}_{\mathrm{A}}-\mathrm{HOMO}_{\mathrm{D}}$ and the use of a small band gap polymer will lower the LUMO of the donor, which does not decreases the Voc value but the $\Delta_{\text {LUMO }}$, which can strongly decrease the charge separation efficiency ${ }^{58}$. Therefore an optimisation of the alignment of the energy levels of the new polymer and acceptor molecules should be done.

The same dependence of Voc with LUMO $-\mathrm{HOMO}_{\mathrm{D}}$ has been encountered with the multilayers cells, with the same controversy on the dependence of Voc with the cathode work function [85, 92]. Indeed, if the Voc value is effectively related to $\triangle\left(\mathrm{LUMO}_{\mathrm{A}}-\mathrm{HOMO}_{\mathrm{D}}\right)$, it depends also of others parameters such as the shunt resistance value (Figure 3), number of interfaces [85]... We have studied a cell family with the structure ITO/Donor/Acceptor/Al/P, with donor $=\mathrm{ZnPc}, \mathrm{CuPc}$, acceptor $=\mathrm{C}_{60}$, PTCDA, PTCDI-C7 and 1,4-DAAQ and P a protective layer from oxygen and humidity contamination, which allows to keep the device in room air after realisation. $\mathrm{P}_{\mathrm{I}}$ corresponds to an encapsulation before breaking the vacuum and $\mathrm{P}_{\mathrm{A}}$ an encapsulation after 5 min of room air exposure ${ }^{106}$. Effectively it is well known that when they are air-exposed there is a strong degradation of the solar cells performances ${ }^{107}$.

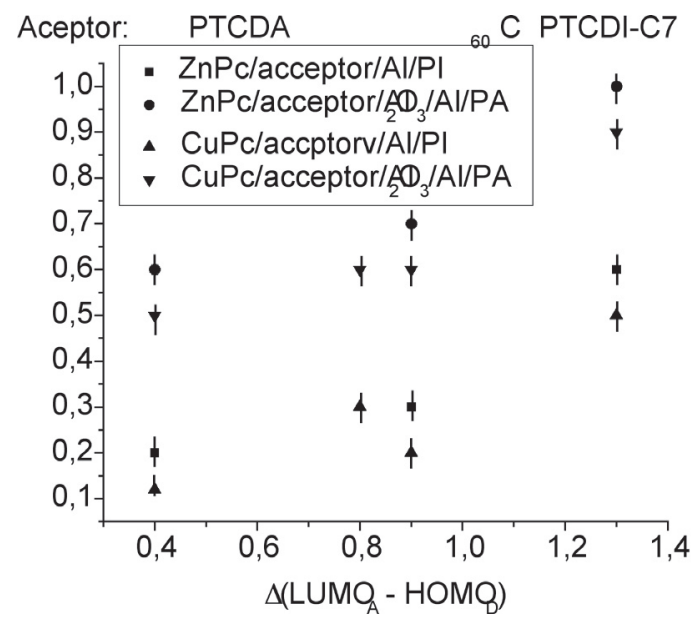

Figure 13: Voc variation with $\Delta\left(\mathrm{LUMO}_{\mathrm{A}}-\mathrm{HOMO}_{\mathrm{D}}\right)$.

It can be seen in figure 13 that, as expected, the voc value increases with the $\Delta\left(\mathrm{LUMO}_{-}-\mathrm{HOMO}_{\mathrm{D}}\right)$. However, it can be seen also that two curve families are clearly visible. One with small Voc values, which corresponds to cell encapsulated without breaking the vacuum and another with higher Voc values, which corresponds to cells encapsulated after $5 \mathrm{~min}$ of air exposure. Since the only difference between these two families is the contact or not with room air, the different behaviour should be attributed to the presence of a thin natural $\mathrm{Al}_{2} \mathrm{O}_{3}$ layer at the interface electron acceptor/aluminium. Such ultra thin $\mathrm{Al}_{2} \mathrm{O}$ layer $(1 \mathrm{~nm})$ increases the shunt resistance value, which justifies the Voc value increase. Such effect of aluminium oxidation on the open circuit voltage has already been proposed by Singh and coll. ${ }^{108,} 109$, thanks to our in situ encapsulation process we have directly put this effect in evidence. We have also worked with $\mathrm{ITO} / \mathrm{CuPc} / \mathrm{C}_{60} / \mathrm{Alq}_{3} / \mathrm{Al} / \mathrm{P}, \mathrm{Alq}_{3}$ being used as $\mathrm{EBL}$ layer. It is shown in table II, that, as expected, the EBL improve significantly the cells performances, while the encapsulation process does not modify the strongly the I-V characteristics.

\begin{tabular}{|c|c|c|}
\hline Devices & $\mathrm{I}_{\mathrm{SC}}$ & Voc \\
\hline $\mathrm{ITO} / \mathrm{CuPc} / \mathrm{C}_{60} / \mathrm{Al} / \mathrm{PI}$ & 4.75 & 0.24 \\
\hline $\mathrm{ITO} / \mathrm{CuPc} / \mathrm{C}_{60} / \mathrm{Al} / \mathrm{PA}$ & 4.40 & 0.41 \\
\hline $\mathrm{ITO} / \mathrm{CuPc} / \mathrm{C}_{60} / \mathrm{Alq}_{3} / \mathrm{Al} / \mathrm{PI}$ & 7.75 & 0.45 \\
\hline $\mathrm{ITO} / \mathrm{CuPc} / \mathrm{C}_{60} / \mathrm{Alq}_{3} / \mathrm{Al} / \mathrm{PA}$ & 7.45 & 0.48 \\
\hline
\end{tabular}

Table II: Isc and Voc values of the different devices under AM1.5 conditions.

Indeed, the Voc value in the presence of $\mathrm{Alq}_{3}$ does not depends strongly on the encapsulation process while it does when simple $\mathrm{CuPc} / \mathrm{C}_{60}$ junction is used. This difference can be explained by the variation of the value of the shunt resistance, Rs. Without $\mathrm{Alq}_{3}$, a thin $\mathrm{Al}_{2} \mathrm{O}_{3}$ layer is necessary to improve Rs and 
therefore Voc, with $\mathrm{Alq}_{3}$, Rs is sufficient and the alumina is not necessary to optimise the Voc value.

These results confirm that if Voc is directly dependant on the $\Delta$ (LUMO $-\mathrm{HOMO}_{\mathrm{D}}$ ) value, others phenomena are determinant for the Voc value such as the shunt resistance and, also, some interface dipole effect. Effectively, about the origin of the open circuit voltage, the influence of thin layer at the interfaces organic/electrode, one of the open issues are the structural and electronic properties of interfaces between organic and inorganic components of the devices. Although the alignment of the chemical potentials at organic/ metal interfaces is now clear for many cases, the interface electronic structures are often discussed ignoring the possible formation of an interfacial electric dipole layer ${ }^{110}$. The type of the interaction at the interface -physorption or chemisorption- can significantly affect the device performance. Charge transfer or chemical reaction was found for organic molecules in contact with several potential electrode materials ${ }^{111}$. XPS and UPS are often used to estimate the dipole potential and investigate the chemical behaviour at the interface. For instance it has been shown that there is a covalent interaction between both $\mathrm{Alq}_{3}$ and $\mathrm{C}_{60}$, while, when $\mathrm{LiF}$ is added between them, it prevents the covalent bonds from forming ${ }^{112}$

About interface layers, it has been shown that the introduction of a thin $\mathrm{LiF}$ layer between the electron acceptor and the aluminium cathode improves the organic optoelectronic devices performances. This effect has been often described in OLEDs $[17,113]$. The increase in luminance and efficiency is attributed to enhancement of the electron injection from the aluminium into the organic acceptor. The $\mathrm{LiF} / \mathrm{Al}$ cathode improves injection by raising the Fermi energy and shifting the effective injection interface deeper into the organic film ${ }^{114}$. Effectively there is Li doping of the organic layer during $\mathrm{Al}$ deposition.

In the case of solar cells, insertion of a thin $\operatorname{LiF}$ layer $(<1.5 \mathrm{~nm})$ at the interface organic/aluminium allows to improve the power conversion efficiency of the cells. An increase in the forward current and in the fill factor is observed upon reducing the serial resistivity across the contact. The optimum LiF thin film thickness is around $1 \mathrm{~nm}$. For higher value the high resistivity of the $\mathrm{LiF}$ decreases its beneficial influence. From (I-V) curves it has been estimated that the insertion of a thin LiF layer decreases the serial resistivity of the diodes by a factor 3-4, while the shunt resistivity is stable ${ }^{115}$. The precise mechanism of $\mathrm{LiF}$ on the interface properties is still under discussion, in the case of solar cells it is not as profitable as in the case of OLEDs.

After a first approach of the electron acceptor/cathode interface, we are going to discuss the cathode/electron donor interface and then will have to go back to the discussion of both interfaces in a more general approach.

Usually the cathode is an ITO (indium tin oxide) film, since others transparent conductive oxides (TCO), such as $\mathrm{ZnO}$ give very poor results. The results presented in figure 14 have been achieved with $\mathrm{TCO} / \mathrm{CuPc} / \mathrm{C}_{60} / \mathrm{Alq}_{3} /$ $\mathrm{Al} / \mathrm{PI}$ samples, where TCO = ITO, ZnO:Al. Both TCO have, in first approach, similar properties such as high transmission $\mathrm{T}$ in the visible $(\mathrm{T} \approx 90 \%)$ and a nominal sheet resistance around $20 \mathrm{Ohm} / \mathrm{square}$. However it can be seen that the power conversion efficiency of the devices with ITO is one order of magnitude higher than that of those with $\mathrm{ZnO}: \mathrm{Al}$ anode which justify that nearly all searcher working in the field of organic solar cells use ITO anode.

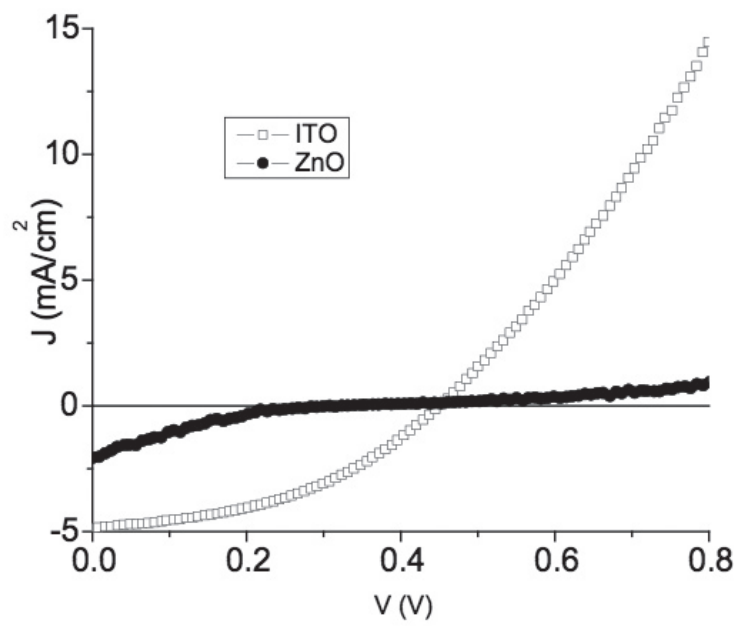

Figure 14: $\mathrm{I}-\mathrm{V}$ characteristics of $\mathrm{TCO} / \mathrm{CuPc} / \mathrm{C} 60 / \mathrm{Alq} 3 / \mathrm{Al} / \mathrm{PI}$, with $\mathrm{TCO}=$ $\mathrm{ZnO}(-\bullet-)$ and ITO (-๑- ).
As shortly discussed above, often organic/electrode interfaces are characterized by the presence of interface dipoles, which generates an electronic potential close of the electrode. According to the interface dipoles, the photo generated charges approaching, the electrode vicinity may either be repelled or attracted towards the electrodes ${ }^{110}$.

The interface dipole potential is defined as a change in work function upon absorption of one mono-layer. An interface dipole with its negative pole pointing towards the organic layer increases the metal work function i.e. decreases the Fermi energy and increases the HOMO energy of the organic material by adding an electrostatic energy, as a result the hole injection barrier is reduced. For a reverse dipole direction electron injection is facilitated. Therefore it is possible to create a dipole, i.e. to control the charge injection in organic based device by chemisorbing molecular species on the metal surface: for example, protonation of ITO, grafting dipolar molecules.... Dipoles can be created by chemisorption (chemical dipole) and physical treatment. Such properties have been used to improve the interface ITO/organic interface properties. Chemical process have been often used to control the work function of ITO in OLEDs [116-119] and passivates ITO surface for solar cells ${ }^{120}$. Physical process generally consist in an oxygen plasma, which is very efficient in improving the ITO thin films properties by decreasing its surface roughness its sheet resistance. In the case of OLEDs it decreases the turn on voltage, increases the brightness and efficiency ${ }^{121-124}$

Usually, as presented during the discussion of the Voc value, with the same goals that the surface treatment, ITO is covered by a thin conducting polymer film, the PEDOT:PSS.

Different buffer layers, others than those evocated above have been probed. The effect of $\mathrm{Au}(30 \mathrm{~nm}), \mathrm{CuPc}(10 \mathrm{~nm})$ has been compared to that of PEDOT: PSS in ITO/buffer layer/P3OT: $\mathrm{C}_{60} / \mathrm{BCP} / \mathrm{LiF} / \mathrm{Al}$ structures. By reference with PEDOT:PSS $(\eta=1.8 \%)$ the Au buffer layer decreases the cell efficiency $(\eta$ $=0.86 \%)$, while $\mathrm{CuPc}$ increases it $((\eta=1.8 \%)[125]$. The efficiency of CuPc is attributed to the reduction of the barrier at the interface, resulting in better hole extraction.

However, if a decrease in barrier height is significant for carrier injection, that is to say in the case of OLED devices, this is questioned for carrier extraction, that is to say in the case of solar cells (figure 15) ${ }^{104}$.

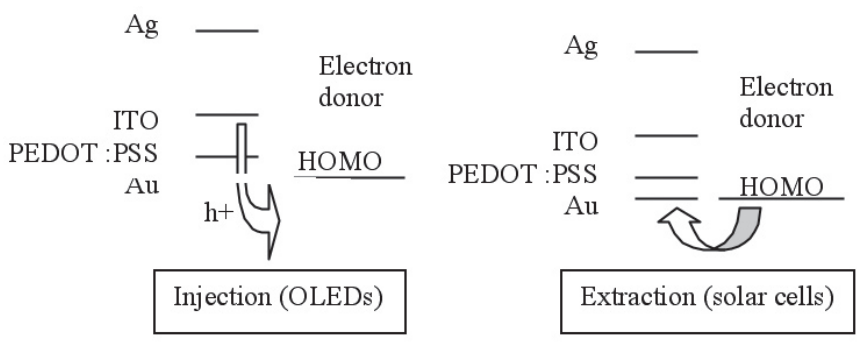

Figure 15: Band diagram scheme at the interface anode/organic material.

If we think, as proposed in ref 104 and 126, carriers injection and extraction seems to not have to overpass the same constraints. If we take into account the band schemes in figure 15 it can be deduced that, in the case of injection, the carrier has to hop above the barrier at the interface and clearly the efficiency of the carrier injection, and therefore that of the device, will increase when the energy difference between the work function of the metal and the HOMO of the organic decreases. In the case of carrier extraction the carrier has to "go down" from the HOMO to the metal work function which, apparently, is not inhibited by the energy difference present at the interface. However, the band scheme in figure 15 , is valuable before electric contact between the metal and the organic material. However the true situation of the band scheme corresponds to that of figure 16 after contact.

The figure 16 is issued from the classical theory of Schottky contact in inorganic material, but it is a good approximation for the materials used in organic solar cells such as metal phtalocyanines, polythiophene derivatives, which behave as semiconductor-like materials [see for example ref 30]. Therefore it appears clearly that, after contact the energy difference between the Fermi level, and therefore between the work function of the metal and the HOMO of the organic should be as small as possible for carrier injection, but also for carrier extraction. This is corroborated by figure 9 . 
$\mathrm{E}_{\mathrm{FM}}$

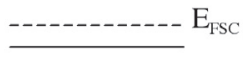

Before contact

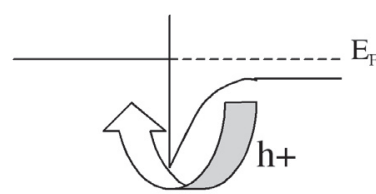

After contact
Figure 16: Band scheme of a contact metal/type p (electron donor).

As shown in figure 14 the cells performances are far better when ITO is used as anode. However if we introduce an ultra thin copper film between the $\mathrm{ZnO}$ and the electron donor, the power conversion efficiency of the solar cell is strongly improved (figure 17).

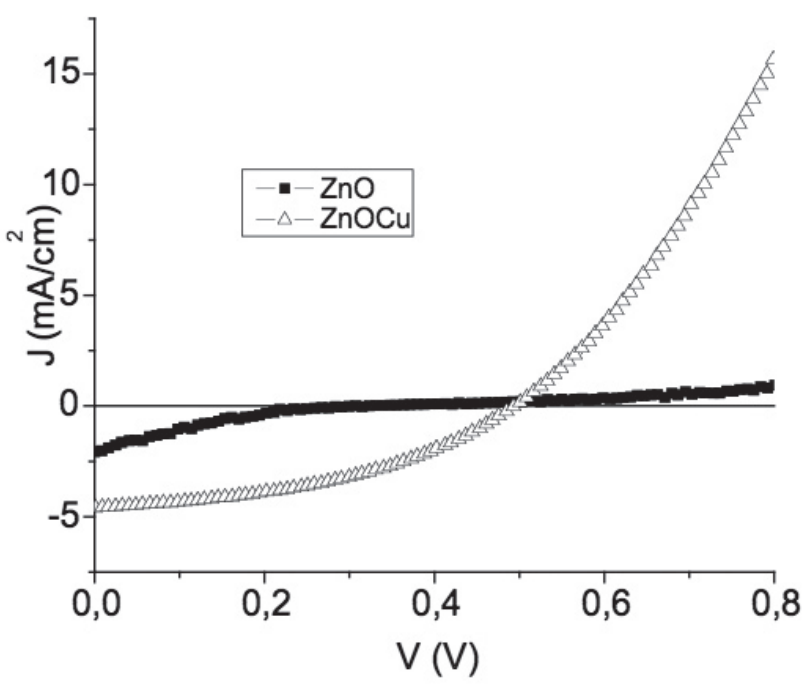

Figure 17: : I-V characteristics of anode/CuPc/C60/Alq3/Al/PI, with anode $=\mathrm{ZnO}(-\bullet-)$ and $\mathrm{ZnO} / \mathrm{Cu}(-\Delta-)$.

Cells ITO/CuPc/C60/Alq3/Al/PI and $\mathrm{ZnO} / \mathrm{Cu} / \mathrm{CuPc} / \mathrm{C} 60 / \mathrm{Alq} 3 / \mathrm{Al} / \mathrm{PI}$ grown in a same run have similar efficiency, in the present case around $1 \%$. Therefore the presence of the ultra thin buffer layer of $\mathrm{Cu}$ improves strongly the performance of the cells using $\mathrm{ZnO}$ as anode, which will permits in the near future to avoid to use the costly and scarce indium in the organic solar cells ${ }^{127}$.

\section{Experimental characterization:}

In order to characterize solar cells, many techniques can be used. We are going to present three of them which are very important, of course the I-V characteristics but also the ultraviolet photoelectron spectroscopy (UPS) and the electrochemistry which both allow to estimating the HOMO and LUMO of the organic materials.

\section{1. I-V characteristics:}

Transport properties of solar cells are of great academic and practical interest. In such devices current voltage behaviour can be either contact or bulk limited ${ }^{128}$. The current voltage (I-V) characteristics of metal/polymer/metal devices are controlled by two basic process: injection of charge carriers from the electrodes into the organic material and vice versa and/or transport of charge in the bulk of the organic film. The current in the device is determined by the less effective mechanism, which limits charge carrier flow. To be injected into the organic film, the charge carriers must overcome the potential barrier at the metal/polymer interface when the contact is not ohmic. For small barriers and/or at high temperature, a large number of charge carriers will have energy large enough to overpass the interface barrier by thermionic emission. In the case of high barrier and/or low temperature, carrier energy usually does not allow thermionic emission and carriers can cross the barrier only by tunnelling. Tunnelling can takes place from metal to the empty states at the LUMO or at the HOMO of the organic. Also, if a high impurity concentration is present in the organic layer, the tunnelling may occurs thought localized states by hopping in the band gap. The less energetic process dominates the injection. The first process discussed is the case where the current is controlled by a potential barrier limitation at the interface metal/organic.

IX.1.1. Potential barrier limitation at the interface metal/organic: discussion.

In the case of rectifying contact, in the forward direction the current density-voltage-characteristics can be described by the thermionic emission theory at a Schottky barrier:

At low voltage, i.e. when Rs is negligible we have:

$$
\mathbf{J}=\mathbf{J}_{\mathrm{s}}\left(\exp \left(\frac{e V}{b k T}-1\right)\right)\left(2^{\prime}\right)
$$

At higher voltage, the series bulk resistance Rs implies as discussed in paragraph III:

$$
\mathbf{J}=\mathbf{J}_{\mathrm{s}}\left(\exp \left(\frac{e(V-J R s)}{b k T}-1\right)\right)
$$

Js is the reverse saturation current density [26]:

$$
\mathrm{JS}_{\mathrm{S}}=\mathrm{A}^{*} \mathrm{~T}^{2} \exp \left(\Phi_{\mathrm{B}} / \mathrm{kT}\right)
$$

With $A *$ the Richardson-Schottky constant, $\phi_{\mathrm{B}}$ barrier height.

In reverse characteristics, when saturation is not respected the $\mathrm{J}$ variation with $\mathrm{V}$ can be interpreted in terms of Schottky effect i.e. image force induced lowering of the potential energy for the charge carrier emission when an electric field is applied.

The current voltage characteristics may be fitted to the RichardsonSchottky emission model. By taking into account the image force lowering we have:

$$
J=A^{*} T^{2} \exp \left(\Phi_{\mathrm{B}} / k T\right) \cdot \operatorname{Exp}\left[\left(\mathrm{q}^{3} \mathrm{~V} / 4 \pi \varepsilon_{\mathrm{o}} \varepsilon_{\mathrm{r}} \mathrm{d}\right)^{1 / 2} / \mathrm{kT}\right]
$$

$\mathrm{d}$ film thickness, $\varepsilon_{0}$ and $\varepsilon_{\mathrm{r}}$ vacuum and relative permittivity, q elementary electronic charge.

A* the Richardson-Schottky constant $\left(\mathrm{A}^{*}=4 \pi \mathrm{qm} * \mathrm{k}^{2} / \mathrm{h}^{3} \# 120 \mathrm{~A} / \mathrm{cm}^{2} \mathrm{~K}\right)$, $\mathrm{m}^{*}$ effective mass. Therefore $\log \left(\mathrm{J} / \mathrm{T}^{2}\right)=\mathrm{f}(1000 / \mathrm{T})$ should gives a straight line with a slope $\left[-\Phi_{\mathrm{B}}+\left(\mathrm{q}^{3} \mathrm{~V} / 4 \pi \varepsilon_{0} \varepsilon_{\mathrm{r}} \mathrm{d}\right)^{1 / 2} / \mathrm{k}\right]$, which gives $\Phi_{\mathrm{B}}=\left(-\mathrm{k}\right.$.slope $+\left(\mathrm{q}^{3} \mathrm{~V} /\right.$ $\left.4 \pi \varepsilon_{0} \varepsilon_{\mathrm{r}}\right)^{1 / 2}(10)$. The second term gives the Schottky coefficient: $\beta_{\mathrm{s}}=\left(\mathrm{q}^{3} /\right.$ $\left.\left(4 \pi \varepsilon_{0} \varepsilon_{r}\right)\right)^{1 / 2}$.

Another possibility for linear dependence of $\log (\mathrm{J})$ versus $\mathrm{V}^{1 / 2}$ is the Poole Frenkel effect (bulk effect: field assisted thermal detrapping of carriers)

Poole Frenkel is a volume effect. It corresponds to the thermal excitation of most carriers of trap level to band valence (in the case of hole carriers) with dropping of coulombian barrier under the action of applied electrical field. The dropping of the barrier is:

$$
\left(\mathrm{q}^{3} \mathrm{~V} /\left(\mathrm{d} \pi \varepsilon_{0} \varepsilon_{\mathrm{r}}\right)\right)^{1 / 2}=\beta_{\mathrm{PF}}(\mathrm{V} / \mathrm{d})^{1 / 2}
$$

Therefore:

$$
\mathrm{J}=\mathrm{Jo} \operatorname{Exp}\left(\beta_{\mathrm{PF}} \mathrm{V}^{1 / 2} / \mathrm{kTd}^{1 / 2}\right)
$$

While for Schottky effect, equation can be rewritten:

$$
\mathrm{J}=\mathrm{Js} \operatorname{Exp}\left(\beta_{\mathrm{s}} \mathrm{V}^{1 / 2} / \mathrm{kTd}^{1 / 2}\right)
$$

Therefore the only difference between the two phenomenon at a given temperature is $2 \beta_{\mathrm{s}}=\beta_{\mathrm{PF}}$ (13), which can allow to discriminate between them.

Moreover if the current density versus field is essentially independent of the electrode material, it strongly suggests that it is bulk controlled. The evolution of the conductivity $\sigma=\mathrm{J} / \mathrm{E}$ with the temperature can be a help in the discrimination between the two phenomena ${ }^{129}$.

In the forward direction, for high fields, tunnelling can takes place. In the case of tunnelling, in such structures, the Fowler Nordheim model is dominant. It invokes tunnelling of electrons trough a triangular barrier and we have: 


$$
\mathrm{J}=\mathrm{AI}^{2} \exp -\left[8 \pi\left(2 \mathrm{~m}^{*}\right)^{1 / 2} \Phi_{\mathrm{B}}^{3 / 2}\right] /(3 \mathrm{hqF})
$$

$\mathrm{m}^{*}$ is the effective charge carrier mass, $\mathrm{F}$ the applied electric field, A(A/ $\left.\mathrm{V}^{2}\right)$ a coefficient that contains the tunnelling prefactor. Therefore, here $\ln \left(\mathrm{J} / \mathrm{F}^{2}\right)$ $=\mathrm{f}(1 / \mathrm{T})$ should give a straight line with a slope $\mathrm{K}=-\left[8 \pi(2 \mathrm{~m} *)^{1 / 2} \Phi_{\mathrm{B}}{ }_{\mathrm{B}}^{3 / 2}\right] /(3 \mathrm{hq})$, which allows to estimate the barrier height for hole (or electron) injection.

In reality the concept of tunnelling alone or of thermionic emission alone does not make sense in transition region. In such region the I-V description would call for some hybrid model. The combined contribution of the two phenomena has been described either as field assisted thermionic emission or thermally activated system (fig 18).

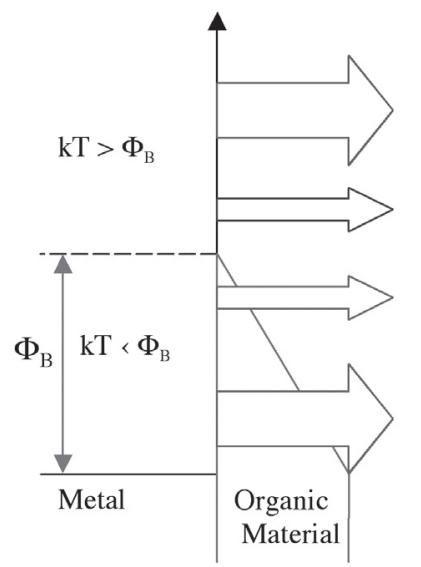

Thermionic emission

Field assisted Thermionic emission

Thermally activated Field emission (tunnelling)

Field emission (tunnelling)

Figure 18: Mechanisms of charge carrier injection through a metal/organic material. contact.

After the discussion of rectifying contact we will discuss the case of ohmic

\section{IX.1.2. Ohmic contact:}

When there is no barrier potential at the contact, it is ohmic. With ohmic contacts, the current voltage relation is linear in the low bias. The slope of log $\mathrm{I}-\log \mathrm{V}$ is then equal to 1: the behaviour is described by Ohm's law (eq 15):

$$
\mathrm{J}_{\mathrm{ohm}}=\mathrm{qn} \mu(\mathrm{V} / \mathrm{d})
$$

here $\mathrm{n}$ is the charge carrier density, $\mathrm{q}$ charge, $\mu$ the carrier mobility, $\mathrm{V}$ the applied voltage, $d$ the organic film thickness. In the case of organic material, the ohmic characteristic can be obtained at low voltage and temperature where current is carried by thermally excited electrons hopping from one molecule to the next.

This condition breaks down at the space charge limit, when the injected carrier density becomes so large that the field due to the carriers themselves dominates over that of the applied bias and then becomes space charge limited. SCLC occurs when the transit time of any excess injected carrier is less than the bulk dielectric relaxation time. In that case the Child's law dominates, if there is no trap (or if they are filled) we have:

$$
\mathrm{J}_{\mathrm{SCLC}}=(9 / 8) \varepsilon_{\mathrm{r}} \varepsilon_{\mathrm{o}} \mu\left(\mathrm{V}^{2} / \mathrm{d}^{3}\right)(15)(16)
$$

SCLC in a device occurs if, at least, one contact is able to inject locally higher carrier density than the material has in thermal equilibrium without carrier injection. In the case of traps unfilled in the material we have:

$$
\mathrm{J}_{\mathrm{SCLC}}=(9 / 8) \varepsilon_{\mathrm{r}} \varepsilon_{\mathrm{o}}(\mathrm{Nc} / \mathrm{Nt})\left(\mathrm{V}^{2} / \mathrm{d}^{3}\right) \exp [-(\mathrm{Ec}-\mathrm{Et}) / \mathrm{kT}]
$$

where $\mathrm{Nc}$ is the effective density of states in the band (here the conduction band) and $\mathrm{Nt}$ is the total concentration of the single dominant trap, (Ec-Et) is the activation energy of the electron traps ${ }^{63}$.

\section{IX.1.3. Discussion of the limiting process:}

In the case of interface potential barrier, for sufficiently high charge injection the current becomes space charge limited. For example at high voltage when tunnelling contributes significantly to charge injection. The electric field at which the transition from contact limited to space charge limited current takes place increases with temperature.

Also if the current is contact limited, the field of transition from thermionic emission to field emission increases with temperature.

It is often difficult to clearly discriminate between the different regimes. One possibility is to select the more clear regimes, i.e. the domains following clearly one of the variation law described above ${ }^{64}$.

Another possibility is to proceed to capacitance-voltage characteristics measurements ${ }^{26,130}$.

\section{IX.1.4. Capacitance measurements:}

The voltage dependence of the capacitance provides a mean to evaluate a carrier concentration in space charge region $\left(\mathrm{N}_{\mathrm{SC}}\right)$ as well as the built in potential $\mathrm{V}_{\mathrm{bi}}$ using:

$$
1 / \mathrm{C}^{2}=\left[2 /\left(\mathrm{q} \varepsilon_{\mathrm{o}} \varepsilon_{\mathrm{r}} \mathrm{N}_{\mathrm{sc}} \mathrm{A}^{2}\right)\right]\left(\mathrm{V}+\mathrm{V}_{\mathrm{bi}}\right)
$$

$\mathrm{C}$ capacitance, $\mathrm{A}$ is the effective area of the device. If a linear relation ship between $1 / C^{2}=f(V)$ is obtained, $N_{s C}$ can be deduced from the slope and $V_{b i}$ from the intercept of the curve with the $\mathrm{x}$ axis. The width of the depletion layer $\mathrm{W}$ and the potential barrier height $\phi_{\mathrm{B}}$ were calculated from:

$$
\begin{gathered}
\mathrm{W}=(2 \mathrm{Vbi} / \mathrm{qNsc}) \\
\Phi_{\mathrm{B}}=\mathrm{Vbi}+(\mathrm{kT}) / \mathrm{q}[\mathrm{Ln}(\mathrm{Nc} / \mathrm{Nsc})+1]
\end{gathered}
$$

Theoretically the curves should not depend on the frequency, this is rarely the case. The must common cause for the frequency dependant capacitance of the device is trapping of electrons by surface states. It is also related to the extremely slow charge transport within the organic and to the low mobility of charge carrier. Therefore, at least, measurement should be done at low frequency $(50 \mathrm{~Hz}-500 \mathrm{~Hz})$.

This model corresponds to simple Schottky contact, in the case of p-n junction, typical values $(\varepsilon, \mathrm{Na}, \mathrm{Nd} . .$.$) of both materials should be introduced...$ In fact these models used in inorganic materials appears very simple and often more sophisticated techniques of capacitance measurements and corresponding theoretical model are necessary ${ }^{131}$.

In order to conclude this part some typical example are presented in figure 19 (I-V).

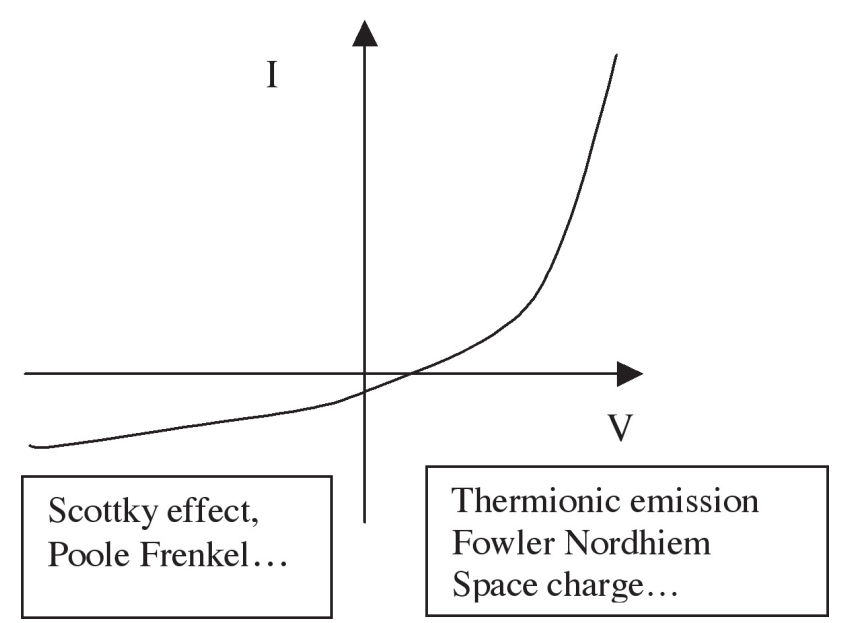

Figure 19: Typical (I-V) curves. 

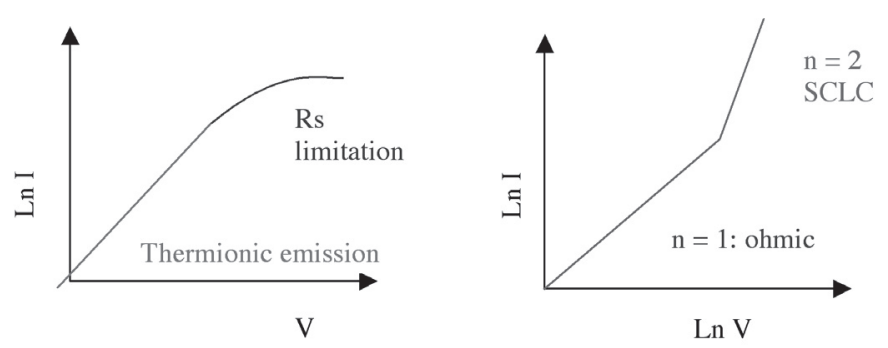

\section{2. ESCA characterisation:}

For the investigation of the chemistry and electronic properties of interfaces, $\mathrm{X}$-ray photoelectron spectroscopy (XPS) and ultraviolet photoelectron spectroscopy (UPS) are valuable tools.

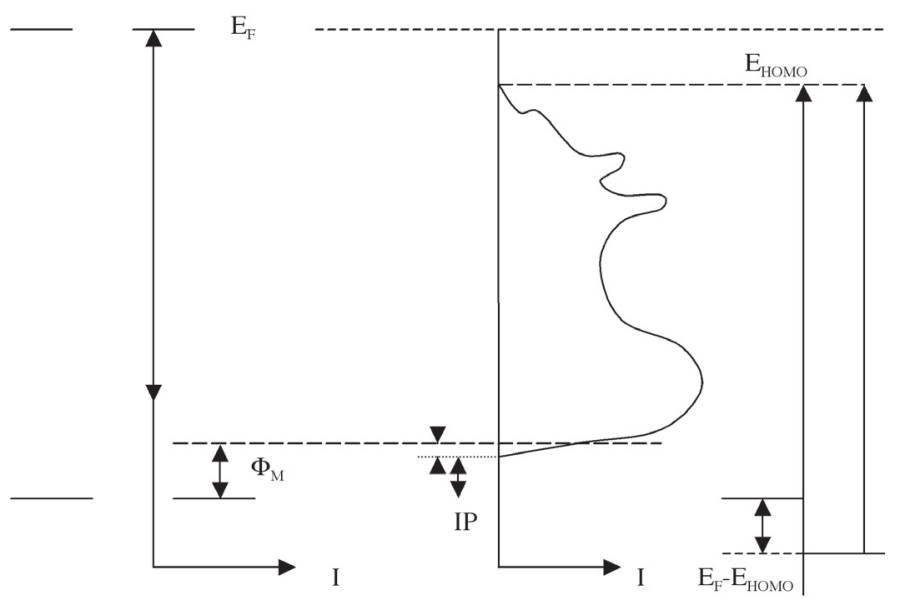

a

b

Figure 20: shows the principle of UPS for the study of an interface: a- clean metal,

b- metal covered with an organic monolayer.

First is presented the UPS spectrum of a clean metal substrate. Electrons below the Fermi level are excited by the uv light and emitted into vacuum. The kinetic energy $E_{\mathrm{kin}}$ distribution of the emitted electrons is called the UPS spectrum and reflects the density of the occupied states of the solid. We have the binding energy $\mathrm{E}_{\mathrm{B}}$ :

$\mathrm{E}_{\mathrm{B}}=\mathrm{h} v-\mathrm{E}_{\mathrm{kin}}-\phi_{\mathrm{SP}}$

hv is the photon energy, $\phi_{\mathrm{SP}}$ spectrometer specific constant (the work function of the spectrometer).

Only photoelectrons whose kinetic energy is higher than the work function $\phi$ of a sample can escape from the surface, consequently $\phi$ can be determined by the difference between the photon energy and the width of the spectrum (fig 20 a). The width of the spectrum is given by the energy separation of the high binding energy cutoff and the Fermi Energy $\left(E_{b}=0\right)$. After deposition of an organic monolayer, possible shifts of the cutoff and thus of the vacuum level suggest the formation of an interfacial dipole layer $\Delta^{110,132,133}$ (fig $20 \mathrm{~b}$ ). In this case the small binding energy onset corresponds to the emission from the highest occupied molecular orbital (HOMO) and the high binding energy (low kinetic energy) cutoff corresponds to the vacuum level at the surface of the organic layer. Therefore as said above we can visualise the relative position of the energy levels at the interface, and examine the difference of the vacuum level between the metal and organic layer which corresponds to $\Delta$ (fig 21).

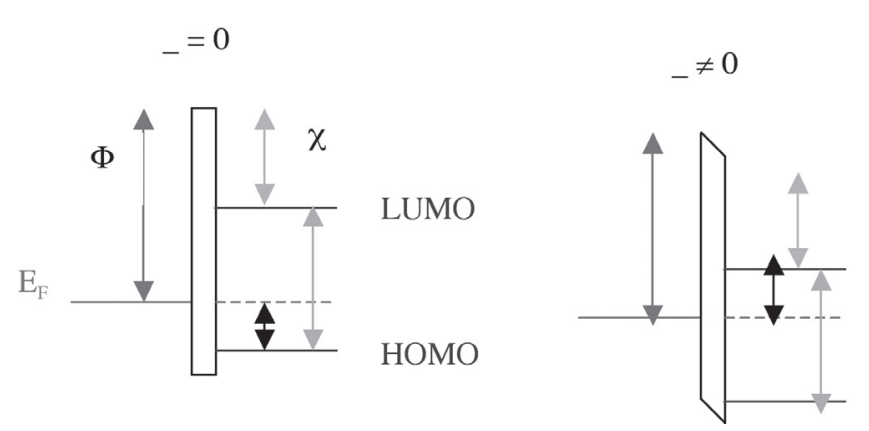

Figure 21: Interfacial dipole $\Delta$ after contact: $\mathrm{a}: \Delta=0, \quad \mathrm{~b}: \Delta \neq 0$.

\section{3. Electrochemical:}

As shown above the HOMO can be clearly measured by XPS. However, a more simple technique allows to estimate the HOMO and LUMO of organic material i.e. electrochemistry.

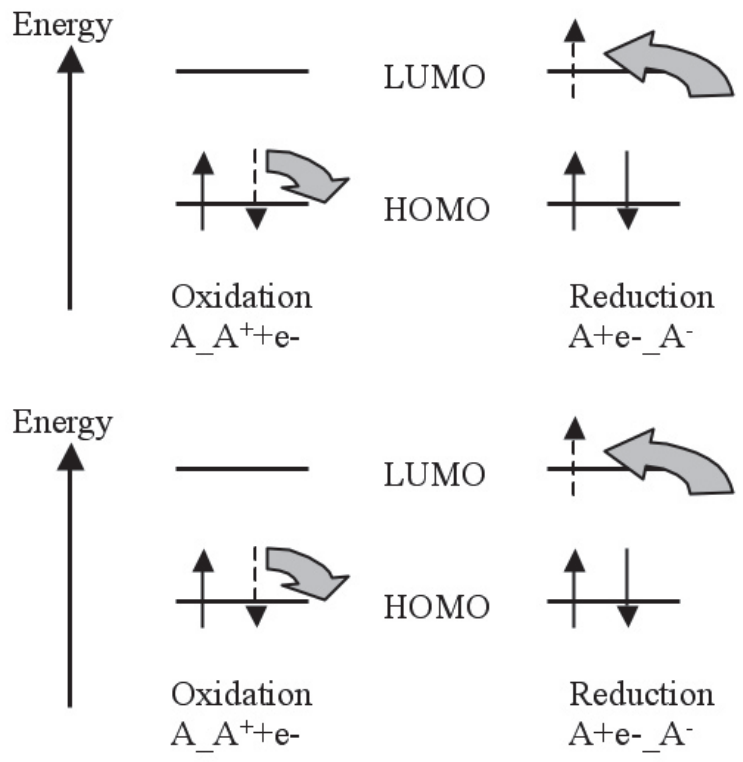

Figure 22: oxidation and reduction of an organic molecule.

When the organic material shows an electron reversible reduction and oxidation wave, cyclic voltammetry (CV) is recognised as an important technique for measuring band gaps, electron affinities (LUMO) and potential ionisations (HOMO). The oxidation process corresponds to removal of charge from the HOMO energy level whereas the reduction cycle corresponds to electron addition to the LUMO (fig 22).

The experimental method is based on cyclic voltammetry 134,135 . The electrochemical set up was based on classical three electrodes cells. The reference electrode was $\mathrm{Ag} / \mathrm{AgCl}$.

The electrochemical reduction and oxidation potentials of the organic material are measured by cyclic voltammetry $(\mathrm{CV})$. When the $\mathrm{CV}$ curves showed a one electron reversible reduction and oxidation wave, the HOMO and LUMO energy can be determined from the first oxidation and reduction potential respectively. The potential difference Eg = LUMO - HOMO can be used to estimate the energy gap of the dye. The energy level of the normal hydrogen electrode (NHE) is situated $4.5 \mathrm{eV}$ below the zero vacuum energy level ${ }^{136}$. From this energy level of the normal hydrogen and the reduction potential of the reference electrode used, for example $\mathrm{Ag} / \mathrm{AgCl}$ i.e. $0.197 \mathrm{~V}$ versus NHE, a simple relation can be written which allows to estimate the both energy values:

LUMO $=[(-4.5)-(0.197-E r e d)] \mathrm{eV}$. $\mathrm{HOMO}=[(-4.5)-(0.197-$ Eox $)] \mathrm{eV}$. 
As an example the curves corresponding to 1.4 Dioaminoanthraquinone (1.4-DAAQ) are presented in fig 23 [136].

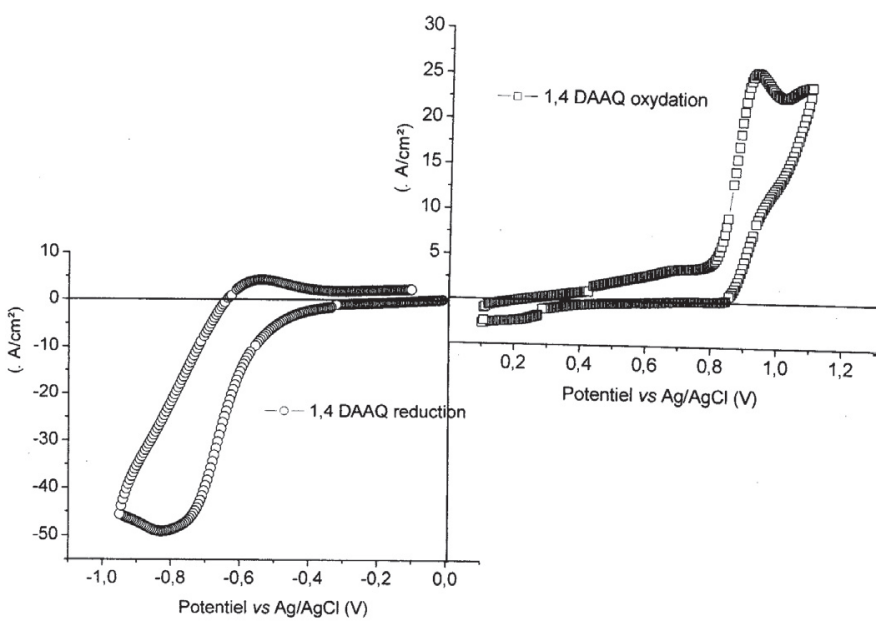

Figure 23: Cyclic voltammogram of 1,4-DAAQ in DMF.

Therefore the band gap can be estimated from the electrochemical measurements, here it is $1.76 \mathrm{eV}$. The value obtained can be compared to the one measured by optical method, $1.8 \mathrm{eV}$, which allows to check the electrochemical measurement ${ }^{137}$.

It should be noted that Kelvin probe study of band binding at organic semiconductor/ metal interface can also be used to study Fermi level alignment for example ${ }^{138}$.

\section{Conclusion - towards the future :}

Since the development of the first commercial application of organic devices (OLED displays), the interest for organic cells becomes increasingly important.

During the last ten years the organic solar cells have known veritable breakthrough, with power conversion efficiency increase from $1 \%$ to $6 \%$. And the searcher groups involved in that field all over the world has steeply grown. Work devoted to these devices increases continuously. At the beginning, the discovery of Tang ${ }^{33}$ in 1986, who shows that efficiency of around $1 \%$ can be achieved using a couple electron donor-electron acceptor. The second event is the success of the new concept of bulk heterojunction. Following these two major contributions, two interactive ways have been expended, both of them give very promising results. A variety of PV technologies centred on concept of interpenetrated and multiheterojunctions structures are the subject of research in the world. Organic solar cells issued from water-soluble poly(thiophene) fullerene heterojunction have been realized ${ }^{139}$. New organic acceptors, with better absorption properties than the fullerene and its derivatives have been synthesized ${ }^{140,141}$. Organic solar cells have been realized on newspaper ${ }^{142}$ Recently it has been shown that the efficiency of an OLED can be improved when integrated with an organic solar cells, while the organic cell allows the recycling of some electrical power ${ }^{143}$. The feasibility of self-rechargeable and flexible polymer solar battery using a thin organic or hybrid solar cell has been shown.

It is well known that the main factor for the superior efficiency of inorganic over organic devices lies in the high intrinsic carrier mobilities that exist in inorganic semiconductor. Higher carrier mobilities mean that charges are transported to the electrodes more quickly, which reduces current losses via recombination. With organic semiconductor the efficiency of devices is limited by inefficiency of hopping charge transport mainly in the case of small conjugated molecules $\left(\mathrm{C}_{60}\right)$. One way to overcome these charge transport limitations is to combine polymers with inorganic semiconductors 144. The charge transfer is favoured between high electron affinity inorganic semiconductors (n-type) and polymer donor with relatively small ionisation potential. Charge transfer rates can be remarkably fast in the case of organics that are chemically bound to micro/nanocrytalline inorganic semiconductors. Therefore colloidal semiconducting nanorods can be used as the inorganic phase in the construction of these solar cells. One dimensional nanorods are preferable because they naturally provide a direct path for electrical transport.
CdSe has been used in such solar cells ${ }^{145}$, the polymer being P3HT. An efficiency of $6.9 \%$ under $0.1 \mathrm{~mW} / \mathrm{cm}^{2}$ illumination at $515 \mathrm{~nm}$ is obtained with a cell ITO/PEDOT:PSS/P3HT:CdSe/Al. Similar study has been done with MEH-PPV [146]. This can be a future successful way for hybrid solar cells.

The photovoltaic market can be separated in different segments: ON-grid, OFF-grid, portables and consumes products etc....The last segment requires lower performance and limited lifetime. Therefore the cells used do not need high power conversion efficiency and lifetime no longer than the consumer product itself, which can correspond quickly to organic solar cells. In that spirit, large-area solar cells have been prepared. The reported efficiencies vary from $0.001 \%$ for $1000 \mathrm{~cm}^{2}$ to around $1 \%$ for $10 \mathrm{~cm}^{2}{ }^{147}$. Indeed, the ultimate combination of all the goals -high efficiency, low cost, stability- necessary to be introduced with some success in the market have not yet resulted simultaneously. A detailed understanding of the degradation of the organic solar cells is still necessary. Atmosphere, light and thermal effects should be studied. If the lifetime represent the device keep more than $50 \%$ of their initial efficiency measured under AM1.5, cells of $6000 \mathrm{~h}$ have been realized 148. The most important environmental parameters that influence the lifetime of organic solar cells are the diffusion of oxygen and water into the device. A possible solution is to include a barrier layer with low oxygen and water permeability, to use a getter... The PEDOT:PSS cannot be use as barrier because it is permeable to oxygen ${ }^{149}$, and, since it is soluble in water, it tends to absorb water, which initiates bubble formation and cell degradation ${ }^{150,}{ }^{107}$. Also, the properties of organic semiconductors are highly sensible to oxygen contamination. The $\mathrm{C}_{60}$ transport properties show considerable degradation as the films absorb oxygen, which induces an increase of the series resistance ${ }^{151}$. Another difficulty is the possible phototodegradation of conjugated organic materials. After photoexcitation, the polymer can react with the oxygen, creating carbonyl type defects eliminating the conjugation. However, in the case of donor/acceptor couple, the ultra-fast photo-induced electron transfer from the donor to the acceptor immediately empties the excited state and lowers strongly the photodegradation probability, which explains the photostabilizing effect of the fullerene in bulk heterojunctions ${ }^{152}$. Therefore, after encapsulation optimization ${ }^{153}$ lifetime compatible with specific applications should be achieved rapidly.

As final outlook, harvesting energy directly from the sunlight using solar panels is being widely recognized as an essential component of future global energy production, provided that photovoltaic energy becomes economically acceptable. Organic bear the potential to develop a new cells generation viable for large scale power generation based on technologies and materials environmentally safe and inexpensive. Organic materials have extremely high optical absorption they can be processed on flexible substrates. Organic solar cells have very short energetic pay-back time. Recent improvement in efficiency and life time shows that organic solar cells will enter the market quickly.

\section{REFERENCES}

1. “A vision for PV technology for 2030 and beyond". Report by PV TRACJuly 2004.

http://europa.eu.int/comm/research/energy/photovoltaics

2. M. Hatcher, Compound Semiconductor 13, 1 20, (2007).

3. J. Bernreuter, Sun \& Wind Energy 1, 92, (2007).

4. H. Inokuchi, Organic Electronics 7, 62, (2006).

5. A. E. Becquerel. Compt. Rend. Acad. Sci. 9, 145, (1839).

6. W. Smith. Nature 7, 303, (1873).

7. A. Pochettino. Acad. Lincei Rend. 15, 355, (1906).

8. H. Hoegel. J. Phys. Chem. 69, 755, (1965).

9. D. M. Chapin, C. S. Fuller, G. L. Pearson. J. Appl. Phys. 25, 676,(1954).

10. J. Zao, A. Wang, M.Green, F. N. Forrazza, App. Phys. Lett. 73, 1991, (1998).

11. K. Ramanathan, M.A. Contreras, C.L. Perkins, S. Asher, F.S. Hasoon, J. Keane, D. Young, M. Romero, W. Metzer, R. Noufi, J. Ward, A. Duda, Prog. Photovolt.: Res. Appl. 11, 225, (2003).

12. P. S. Revcroft, H. Ulal. Sol. Ener. Mater. 2, 217, (1979/1980).

13. G. Horowitz. Adv. Mater. 2, 287, (1990).

14. N. Minami, K. Sasaki, K. Tsuda, J. Appl. Phys. 54, 6764, (1983).

15. H. Sasabe, T. Furuno, K. Takimoto. Synthetic Metals. 28, c 787, (1989).

16. N. S. Sariciftci. Sciences 258, 1474, (1992).

N. S. Sariciftci, D. Braun, C. Zhang, V. I. Srdanov, A. S. Heeger, G. Stucky, F. Wuld. Appl. Phys. Lett. 62, 585, (1993). 
17. J. C. Bernède, V. Jousseaume, M. A. Del Valle, F. R. Diaz in Current Trends in polymer Sciences, "From the organic electroluminescent diodes to the new organic photovoltaic cells", Vol 6, 2001, pp.135-.

18. Y.B. Yoon, T.W. Kim, H.W. Yang, J.H. Kim, J.H. Seo, Y.K. Kim, Thin slid Films 515, 5095, (2007).

19. J. J. M. Halls, K. Pickler, R. H. Friend, S. C. Moratti, A. B. Holmes. Appl. Phys. Lett. 68, 3120, (1996).

20. S. E. Shoheen, C. J. Brabec, N. S. Sariciftci, F. Padinger, J. Fromherz, J. C. Hummelen. Appl. Phys. Lett. 78, 841, (2001).

21. P. Peumans, S. R. Forrest, App. Phys. Lett. 79, 126, (2001).

22. T. Suzuti, Y. Shirota, J. Rostalski, D. Meissner. Solar Energy Mater. Solar Cells. 61, 1, (2000).

23. K. Kim, J.Liu, M.A.G. Namboothiry, D.L. Carroll, Appl. Phys. Lett. 90, $163511,(2007)$

24. J. Xue, S. Uchida, B.P. Rand, S.R. Forrest, Appl. Phys Lett. 85, 5757, (2004).

25. H. Mathieu. Physique des semiconducteurs et des composants électroniques, 2d Edition, Masson Editor, Paris, 1990.

26. S. M. Sze Physics of semiconductor devices, $2^{\text {nd }}$ Edition. Editor John Wiley \& Sons, New York, 1981.

27. T. A. Abdalla, W. Mammo, B. Workalemahu. Synthetic Metals, 144, 213, (2004).

28. F. T. Reis, D. Mencaraglia, S. Ould Saad, J. Seguy, M. Oukachmih, P. Jolinat, P. Destruel, Journal Non Crystalline Solids 338-340, 599, (2004).

29. G. D. Sharma, S. K. Sharma, M. S. Roy, Thin Solid Films, 468, 208, (2004).

30. H. Spanggaard, F. C. Krebs. Solar Energy Materials \& Solar Cells 83, $125,(2004)$

31. J. J. M. Halls, R. H. Friend. Synth. Met. 85, 1307, (1997).

32. H. Yonehara, C. Pac. Thin Solid Films 278, 108, (1996).

33. C. W. Tang. Appl. Phys. Lett. 48, 183, (1986).

34. L. Sicot, C. Fiovini, A. Lorin, P. Raimond, C. Sentein, J. M. Nunzi. Sol. Energ. Mat. Solar Cells 63, 49, (2000).

35. K. Tahahashi, N. Kuraya, T. Yamaguchi, T. Komura, K. Murata. Sol. Ener. Mater. \& Solar Cells, 61, 403, (2000).

36. M. Pfeiffer, A. Beyer, B. Ploinnings, A. Nallau, T. Fritz, K. Leo, D. Schlettwein, S. Hiller, D. Wohrle. Sol. Energ. Mat. \& Solar Cells, 63, 83, (2000).

37. J. Drechsel, B. Maenning, F. Kozlowski, M. Pfeiffer, K. Leo,. Appl. Phys. Lett. 86, 244102, (2005).

38. H. Derouiche, J.C. Bernède, J. L'Hyver, Dyes and Pigments 63, 277, (2004).

39. M. Hiramoto, H. Fukusumi, M. Yokoyama. Appl. Phys. Lett. 58, 1062 , (1991).

40. G. Yu, K. Pakboz, A. J. Heeger. Appl. Phys. Lett. 64, 3422, (1994).

41. J. C. Hummelen, B. W. Knight, F. Le Peq, F. Wudl, J. Yao, C. L. Wilkins. J. Org. Chem. 60, 532, (1995).

42. C. J. Brabec., N. S. Sariciftci. J. C. Hummelen. Adv. Func. Mater. 11, 15, (2001).

43. S. E. Shaheen, C. J. Brabec, F. Padinger, T. Fromherz, J. C. Hummelen, N. S. Sraiciftci. Appl. Phys. Lett. 78, 1, (2001).

44. C. J. Brabec, F. Padinger, J. C. Hummelen, R. A. J. Janssen, N. S. Sariciftci. Synthetic metals 102, 861, (1999).

45. D. Gebeychu, C. J. Brabec, F. Padinger, T. Fromherz, J. C. Hummelen, D. Badt, H. Schinlder, N. S. Sariciftci. Synthetic metals 118, 1, (2001).

46. T. Jeranko, H. Tributsch, N. S. Sariciftci, J. C. Hummelen, Solar Energy Mater \& Solar Cells 83, 247, (2004)

47. C. J. Brabec. Solar Energy Materials \& Solar Cells 83, 273, (2004).

48. J. J. Dittmer, R. Lazzaromi, Ph. Leclère, P. Moretti, M. Granström, K. Petritsch, E. A. Marseglia, R. H. Friend, J. L. Bredas, H. Rost, A. B. Holmes. Solar Energy Materials \& Solar Cells 61, 53, (2000).

49. J. Rostalski, D. Meissner. Sol. Energy Mater. Solar Cells 61, 87, (2000).

50. A. J. Breeze, Z. Schlesinger, S. A. Carter, H. Tillmann, H. H. Hörhold. Solar Energy Materials \& Solar Cells. 83, 263, (2004).

51. L. Schmidt-Mende, A. Fechtenkötter, K. Müllen, R. H. Friend, J. D. MacKenzie. Physica E 14, 263, (2002).

52. F. Zang, M. Sevensson, M. R. Anderson, M. Maggini, S. Bucella, E. Menna, O. Inganäs. Ads. Mater. 13, 1871, (2002).

53. H. Neugebauer, M. A. Loi, C. Winder, N. S. Sariciftci, G. Cerullo, A. Gouloumis, P. Vazquez, T. Torres. Solar Energy Materials \& Solar Cells 83, 201, (2004).
54. A. Yassar, C. Videlot, A. Jaafari, Sol. Energy Mater. Solar Cells 90, 916, (2006).

55. K. C. Krebs, O. Hagemann, M. Jorgensen. Solar Energy Materials \& Solar Cells 83, 2110, (2004).

56. S. S. Sun. Solar Energy Materials \& Solar Cells 79, 257, (2003).

57. G. Dennler, A.J. Mozer, G. Juska, A. Pivrikas, R. Österbacka, A. Fuchsbauer, N.S. Sariciftci, Org. Electron. 7, 229, (2006).58] E. Bundgaard, F.C. Krebs, Solar Energy Materials \& Solar Cells 91, 954, (2007).

59. G. Li, V. Shrotriya, J. Huang, Y. Yao, T. Moriarty, K. Emery, Y. Yang, Nature Materials 4, 864, (2005).

60. Y. Kim, S. Cook, S.M. Tuladhar, S.A. Choulis, J. Nelson, J.R. Durrant, D.D.C. Bradley, M. Giles, I. McCulloch, C-S. Ha, M. Ree, Nature Materials 5, 197, (2006).

61. P. Vanlaeke, A. Swinnen, I. Haeldermans, G. Vanhoyland, T. Aernouts, D. Cheyns, C. Deibel, J. D'Haen, P. Heremans, J. Poortmans, J.V. Manca, Solar Energy Materials \& Solar Cells 90, 2150, (2006).

62. Y. Zhao, Z. Xie, Y. Qu, Y. Geng, L. Wang, Appl. Phys. Lett. 90, 043504, (2007).

63. S. Rait, S. Kashyap, P.K. Bhatnagar, P.C. Mathur, S.K. Sengupta, J. Kumar, Solar Energy Materials \& Solar Cells 91, 757, (2007).

64. W. Wang, H-B. Wu, C-Y. Yang, C. Luo, Y. Zhang, J-W Chen, Y. Cao, Appl; Phys. Lett. 90, 183512, (2007).

65. S-H Jin, B.V. Kumar Naidu, H-S Jeon, S-M Park, J-S. Park, S. C. Kim, J. W. Lee, Y-S. Gal, Solar Energy Materials \& Solar Cells 91, 1187, (2007).

66. M. Reyes-Reyes, K. Kim, D.L. Carroll, Appl. Phys. Lett. 87, 083506 , (2005).

67. W. Ma, C. Yang, K. Lee, A.J. Heeger, Adv. Func. Mater. 15, 1617, (2005).

68. G. Li, V. Shrotiya, Y. Yao, Y. Yang, J. Appl. Phys. 98, 043704, (2005).

69. P. Vanlaeke, A. Swinnen, I. Haeldermans, G. Vanhoyland, T. Aernouts, D. Cheyns, C. Deibel, J. D'Haen, P. Heremans, J. Poortmans, J.V. Manca, Solar Energy Materials \& Solar Cells 90, 2150, (2006).

70. H. Kim, W-W. So, S-J. Moon, Solar Energy Materials \& Solar Cells 91 , 581, (2007)

71. P. Vanlaeke, G. Vanhoyland, T. Aernouts, D. Cheyns, C. Deibel, J. Manca, P. Heremans, J. Poortmans, Thin Solid Films 511-512, 358, (2006).

72. C. He, Q. He, Y. He, Y. Li, F. Bai, C. Yang, Y. Ding, L. Wang, J. Ye, Solar Energy Materials \& Solar Cells 90, 1815, (2006).

73. J. Li, T. Osara, Y. Hirayama, T. Sano, K. Wakisada, M. Matsumura, Solar Energy Materials \& Solar Cells 91, 745, (2007).

74. M. M. Mandoc, W. Veurman, L.J.A. Koster, M..M. Koetse, J. Sweelssen, B. De Boer, P.W.M. Blom, J. Appl. Phys. 101, 104512, (2007).

75. P. Peumans, S.R. Forrest, Appl. Phys. Lett. 79, 126, (2001).

76. M. Vogel, S. Doka, Ch. Breyer, M. Ch. Lux-Steiner, K. Fostiropoulos, Appl. Phys. Lett. 89, 163501, (2006).

77. B.P. Rand, J. Li, J. Xue, R.J. Holmes, M.E. Thompson, S.R. Forrest, $A d v$ Mater. 17, 2714, (2005)

78. M.Y. Chan, C.S. Lee, S.L. Lai, M.K. Fung, F.L. Wong, H.Y. Sun, K.M. Lau, S.T. Lee, J. Appl. Phys. 100, 094506, (2006).

79. Z.R. Hong, Z.H. Huang, X.T. Zeng, Chem. Phys. Lett. 425, 62, (2006).

80. B. Brousse, B. Ratier, A. Moliton, Thin Solid Films 451-452, 81, (2004).

81. M. Vogel, J. Strotmann, B. Johnev, M. Ch. Lux Steiner, K. Fostiropoulos, Thin Solid Films 511-512, 367, (2006).

82. J. Xue, B.P. Rand, S. Uchida, S.R. Forrest, Adv. Mater. 17, 66, (2005).

83. B.P. Rand, J. Xue, S. Uchida, S.R. Forrest, J. Appl. Phys. 98, 124902 , (2005).

84. J. Xue, B.P. Rand, S. Uchida, S.R. Forrest, J. Appl. Phys. 98, 124903 , (2005).

85. M.Y. Chan, S.L. Lai, M.K. Fung, C.S. Lee, S.T. Lee, Appl. Phys. Lett. 90 , 023504, (2007).

86. D. Gebeyehu, B. Maenning, J. Dreschel, K. Leo, M. Pfeiffer, Solar Energy Materials \& Solar Cells 79, 81, (2003).

87. P. Peumans, A. Yakimov, S.T. Forrest, J. Appl. Phys. 93, 3693, (2003).

88. A. Yakimov, S.R. Forrest, Appl. Phys. Lett: 80, 1667, (2002).

89. K. Triyana, T. Yasuda, K. Fujita, T. Tsutsui, Thin Solid Films 477, 198, (2005).

90. A. Colsmann, J. Junge, C. Kayser, U. Lemmer, Appl. Phys. Lett. 89, 203506, (2006).

91. J. Gilot, M.M. Wienk, R.A.J. Janssen, Appl. Phys. Lett. 90, 143512, (2007).

92. B.P. Rand, D.P. Burk, S.R. Forrest, Phys. Rev. B 75, 115327, (2007). 
93. A.C. Mayer, M.t. Lloyd, D.J. Herman, T.G. Kasen, G.G. Mallaras, Appl. Phys; Lett. 85, 6272, (2004).

94. S. Yoo, B. Domercq, B. Kippelen, Appl. Phys. Lett. 85, 5427, (2004).

95. M. Oukachmih, P. Destruel, I. Seguy, G. Ablart, P. Jolinat, S. Archambeau, M. Mabiala, S. Fouet., H. Bock. Solar Energy Mater \& Solar Cells, 85, $535,(2005)$.

96. S. Archambeau, I. Séguy, p. Jolinat, j. Farenc, P. Destruel, T.P. Nguyen, H. Bock, E. Grelet, Appl. Surf. Sciences 253, 2078, (2006).

97. E. Kymakis, E. Koudoumas, I. Franghiadakis, Solar Energy Mater \& Solar Cells 90, 1705, (2006).

98. S.K.M.Jönsson, W.R. Salaneck, M. Fahlman, J. Appl. Phys. 98, 014901$1,(2005)$.

99. V. Dyakanov. Physica E 1453 (2002).

100. C. J. Brabec, A. Cravino, D. Meisner, N. S. Sariciftci, T. Fromherz, M. T. Rispens, L. Sanchez, J. C. Hummelen. Adv. Func. Mat. 11, 374, (2001).

101. C. J. Brabec, A. Cravino, D. Meisner, N. S. Sariciftci, M. T. Rispens, L. Sanchez, J. C. Hummelen, T. Fromherz. Thin Solid Films 403-404, 368, (2002).

102. H. Frohne, S. E. Shaheen, C. J. Brabec, D. C. Müller, N. S. Sariciftci, K. Meerhalz. Chem. Phys. Lett. 77, 3096, (2000).

103. A. Petr, F. Zhang, H. Petseng, M. Knupfer, L. Dunsch. Chem. Phys. Lett. 385, 140, (2004).

104. P.W.M. Bloom, V.D. Mihailatchi, L.J.A. Koster, D.E. Markov, $A d v$. Mater. 19, 1551, (2007)

105. S-S. Sun, Solar Energy Mater \& Solar Cells 85, 261, (2005).

106. N. Karst, J.C. Bernède, Phys. Stat. Sol. (a) 203, R70, (2006).

107. K. Kawano, R. Pacios, D. Poplavskyy, J. Nelson, D.D.C. Bradley, J.R. Durrant, Solar Energy Materials \& Solar Cells 90, 3520, (2006).

108. V.P. Singh, R.S. Singh, B. Parthasarathy, A Aguilera, J. Antony, M. Payne, Appl. Phys. Lett. 86, 082106, (2005).

109. V.P. Singh, B. Parthasarathy, R.S. Singh, A Aguilera, J. Antony, M. Payne, Solar Energy Materials and Solar Cells 90, 798, (2006).

110. X. Crispin. Solar Energy Materials \& Solar Cells 83, 147, (2004).

111. M. Knupfer, H. Preisert. Phys. Stat. Sol. (a) 201, 1055, (2004).

112. S.K.M. Jösson, W.R. Salaneck, M. Fahlman, J. Appl. Phys. 98, 014901, (2005).

113. L. S. Hung, C. H. Chen. Materials Science and Engineering R 39, 143, (2002).

114. M.A.M. Baldo, S.R. Forrest, Phys. Rev. B 64, 085201, (2001).

115. C.J. Brabec, J. E. Shaheen, C. Winder, N.S. Sariciftci, P. Denk. Appl. Phys. Lett. 80, 1, (2002).

116. -F. Nüesch, L.J. Rotberg, E.W. Forsythe, Q. Toan Le, Y. Gao, Appl. Phys. Lett.74, 880, (1999).

117. E.L. Bruner, N. Koch, A. R. Span, S.L. Bernasek, A. Kahn, J. Schartz, $J$ Am. Chem. Soc. 124, 3192, (2002).

118. S. Kato, J. Am. Chem. Soc. 127, 11538, (2005).

119. E.L. Hanson, J. Guo, N. Koch, J. Schartz, S.L. Bernasek, J. Am. Chem. Soc. 127, 10058, (2005)

120. B. Johnev, M. Vogel, K. Fostiropoulos, B. Mertesacker, M. Rusu, M.-C. Lux-Steiner, A. Weidinger, Thin Solid Films 488, 270, (2005).

121. I-M. Chan, W-C. Cheng, F.C. Hong, Appl. Phys. Lett. 80, 13, (2002).

122. H-T. Lu, M. Yokoyama, J. Cryst. Growth 260, 186, (2004).

123. C.N. Li, C.Y. Kwong, A.B. Djurisic, P.T. Lai, P.C. Chui, W.K. Chan, S.Y. Liu, Thin Solid Films 477, 57, (2005).

124. Z. Y. Zhong, Y. D. Jiang, Phys. Stat. Sol. (a) 203, 3882, (2006).
125. I. Yoo, M. Lee, C. Lee, D-W. Kim, In S. Moon, D-H. Hwang, Synthetic Metals 153, 97, (2005).

126. V. D. Mihailetchi, L. J. A. Koster, P.W.M. Blom, Appl. Phys. Lett; 85, 970, (2004).

127. J.C. Bernède French Patent no. BF07/05502 (27/7/2007)

128. Z. Chiguvare, J. Parisi, V. Dyakonove. J. Appl. Phys. 94, 2440,(2003).

129. G. Safoula, K. Napo, J. C. Bernède, S. Touihri, K. Alimi. Eur. Pol. Jour. 37 (2001) 843.

130. M. S. Roy, G. D. Sharma, S. K. Gupta. Thin Solid Films 310, 279, (1997).

131. F. F. Reis, D. Mencaraglia, S. Ould Saad, I. Seguy, M. Oukachunih, P. Jolinat, P. Destruel. Journal of non crystalline Solids 338-340, 599, (2004).

132. Th. Kugler, W. R. Salaneck, H. Rast, A. B. Holmes. Chem. Phys. Lett. 310391 (1999).

133. K. Seki, E. Ito, H. Ishii. Synthetic Metals 91, 137, (1997).

134. Y. Li, Y. Cao, D. Wang, G. Yu, A. S. Heeger. Synthetic Metals 99, 243, (1999).

135. R. Cervini, X. C. Li, G. W. C. Spences, A. B. Holmes, S. C. Moratti, R. H. Friend. Synthetic Metals 84, 359, (1997).

136. F. Brovelli, B.L. Rivas, J. C. Bernède, M. A. Del Vallé, F. R. Diaz, Poly. Bull. 58, 521, (2007)

137. M. Jamali, J. C. Bernède, C. Rabiller, J. Sol. State Chem. 141, 309, (1998).

138. H. Ishii, N. Hayashi, E. Ito, Y. Washizu, K. Sugi, Y. Kimura, M. Niwana, Y. Ouchi, K. Seki. Phys. Stat. Sol. (a) 201, 1075, (2004).

139. J. Yang, A. Garcia, T-Q Nguyen, Appl. Phys. Lett. 90, 103514, (2007).

140. J-K Lee, K. Fujida, t. Tsutsui, M-R Kim, Solar Energy Materials \& Solar Cells 91, 892, ( 2007).

141. R. Koeppe, O. Bossart, G. Calzaferi, N.S. Sariciftci, Sol. Energy Mater. \& Solar Cells 91, 986, (2007).

142. B. Lamprecht, R. Thünauer, M. Ostermann, G. Jakopic, G. Leising, Phys. Stat. Sol. (a) 202, R50, (2005).

143. C-J. Yang, T-Y. Cho, C-L. Lin, C-C. Wu, Appl. Phys. Lett. 90, 173507 (2007).

144. W. U. Huynh, J. J. Dïttmer, A. P. Alivisatos. Science 295, 2425, (2002).

145. W. G. Greenham, X. Peng, P. Alivisatos. Phys. Rev. 54, 17628, (1996).

146. R. L. D. Whitby, W. K. Asu, T. H. Lee, C. B. Boothroyd, H. N. Kroto, D. R. M. Waltan. Chem. Phys. Lett. 359, 68, (2002).

147. E. Bundgaard, F.C. Krebs, Solar Energy Materials \& Solar Cells 91, $1019,(2007)$.

148. Lungenschmied, G. Dennler, H. Neugebauer, S. N. Sariciftci, M. Glatthar, T. Meyer, A. Meyer, Solar Energy Materials \& Solar Cells 91, 379, (2007).

149. M. Andersen, J.E. Carlé, N. Cruys-bagger, M.R. Lilliedal, M.A. Hammond, B. Winther-Jensen, F.C. Krebs, Solar Energy Materials \& Solar Cells 91, 539, (2007).

150. S-C. Luo, H-H. Chung, E.T. Pashuck, E.P. Douglas, P.H. Holloway, Thin Solid Films, 478, 326, (2005).

151. M. Rusu, J. Strotmann, M. Vogel, M.Ch Lux Steiner, F. Fostiropoulos, Appl. Phys. Lett. 90, 153511, (2007).

152. J. Brabec, N.S. sariciftci, J.C. Hummelen, Adv. Funct. Mater. 11, 15, (2001).

153. P. Madakasira, K. Inoue, R. Ulbricht, S.B. Lee, M. Zhou, J.P. Ferraris, A.A. Zakhidov, Synthetic Metals 155, 332, (2005). 